\title{
High-Velocity Impacts of Pyrophoric Alloy Fragments on Thin Armour Steel Plates
}

\author{
Evaristo Santamaria Ferraro ${ }^{1,2, *}$, Marina Seidl ${ }^{1}$, Tom De Vuyst ${ }^{2}$ and Norbert Faderl ${ }^{1}$ \\ 1 French-German Research Institute of Saint Louis (ISL), 68300 Saint Louis, France; marina.seidl@isl.eu (M.S.); \\ norbert.faderl@isl.eu (N.F.) \\ 2 School of Physics, Engineering and Computer Science, University of Hertfordshire, Hatfield AL109EU, UK; \\ t.de-vuyst@herts.ac.uk \\ * Correspondence: evaristo.santamaria-ferraro@isl.eu; Tel.: +33-751-242-523
}

Citation: Santamaria Ferraro, E.; Seidl, M.; De Vuyst, T.; Faderl, N. High-Velocity Impacts of Pyrophoric Alloy Fragments on Thin Armour Steel Plates. Materials 2021, 14, 4649. https://doi.org/10.3390/ ma14164649

Academic Editors: Erhardt Lach and Teresa Fras

Received: 29 June 2021

Accepted: 10 August 2021

Published: 18 August 2021

Publisher's Note: MDPI stays neutral with regard to jurisdictional claims in published maps and institutional affiliations.

Copyright: (c) 2021 by the authors. Licensee MDPI, Basel, Switzerland. This article is an open access article distributed under the terms and conditions of the Creative Commons Attribution (CC BY) license (https:// creativecommons.org/licenses/by/ $4.0 /)$.

\begin{abstract}
The terminal ballistics effects of Intermetallic Reactive Materials (IRM) fragments have been the object of intense research in recent years. IRM fragments flying at velocities up to $2000 \mathrm{~m} / \mathrm{s}$ represent a realistic threat in modern warfare scenarios as these materials are substituting conventional solutions in defense applications. The IRM add Impact Induced Energy Release (IIER) to the mechanical interaction with a target. Therefore, the necessity of investigations on IIER to quantify potential threats to existing protection systems. In this study, Mixed Rare Earths (MRE) fragments were used due to the mechanical and pyrophoric affinity with IRM, the commercial availability and cost-effectiveness. High-Velocity Impacts (HVI) of MRE were performed at velocities ranging from 800 to $1600 \mathrm{~m} / \mathrm{s}$ and recorded using a high-speed camera. 70 MREs cylindrical fragments and 24 steel fragments were shot on armour steel plates with thicknesses ranging from $2 \mathrm{~mm}$ to $3 \mathrm{~mm}$. The influence of the impact pitch angle $(\alpha)$ on HVI outcomes was assessed, defining a threshold value at $\alpha$ of $20^{\circ}$. The influence of the failure modes of MRE and steel fragments on the critical impact velocities $(C I V)$ and critical kinetic energy $\left(\mathrm{E}_{\mathrm{kin}}\right.$ crit $)$ was evaluated. An energy-based model was developed and fitted with sufficient accuracy the Normalised $\mathrm{E}_{\text {Kin crit }}\left(\widetilde{E}_{\text {kin }}^{\text {crit }}\right)$ determined from the experiments. IIER was observed in all the experiments involving MRE. From the analyses, it was observed that the IIER spreads behind the targets with velocities comparable to the residual velocities of plugs and shattered fragment.
\end{abstract}

Keywords: reactive materials; impact-induced energy release; high-velocity impact; pyrophoric alloys

\section{Introduction}

The interest of the defence industry towards Intermetallic Reactive Materials (IRM) is related to their structural properties, combined with the exothermal reaction triggered by a thermal or mechanical shock, as discussed by Aydelotte [1].

IRM represent a valid substitute for inert casings of next-generation warheads, augmenting the post-detonation lethality abundantly. The scheme in Figure 1 shows how small IRM fragments are generated and accelerated: after the detonation (a), the IRM bomb casing fractures into fragments (b), which are then accelerated by the detonation gases and the blast wave (c), reaching velocities up to $2000 \mathrm{~m} / \mathrm{s}$ and covering a lethality range significantly higher than the one covered by the blast, as Aydelotte [1] reported. The IRM fragments will eventually interact with a target, triggering the Impact Induced Energy Release (IIER) (d).

The IIER of fragments is the focus of this work. In order to set up a coherent and reproducible methodology, High-Velocity Impacts (HVI) experiments were performed using a ballistic set-up, shooting commercial Mixed Rare Earths (MREs) cylindrical samples, with diameters of $3.5 \mathrm{~mm}$ and $5 \mathrm{~mm}$ and length $L$ over diameter $d$ ratios $(L / d)$ of 1 . 


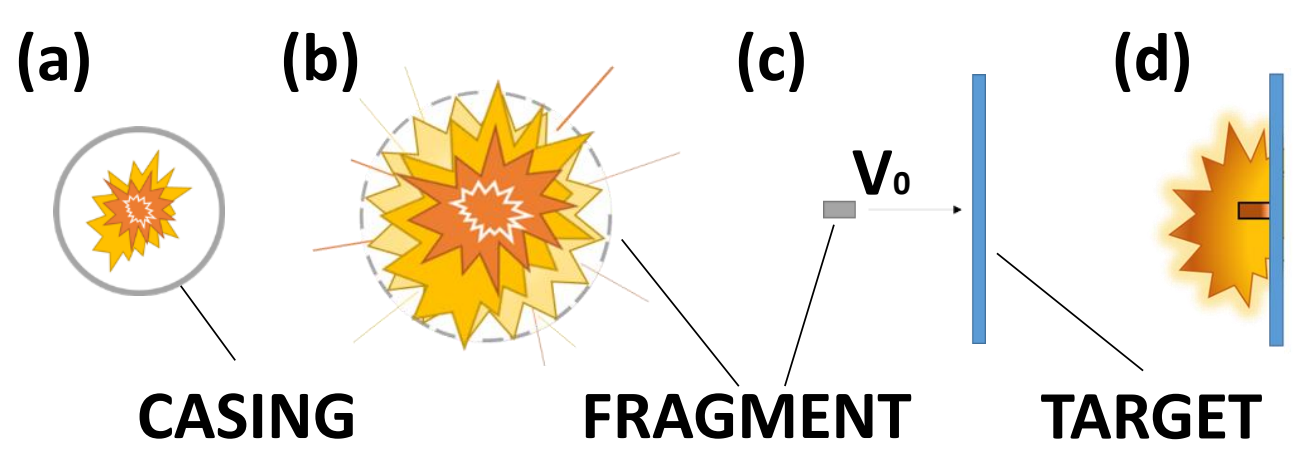

Figure 1. Schematic representation of bomb detonation (a); case fragmentation (b); fragment flight accelerated by the blast (d); impact with target and impact-induced energy release (c).

MREs fragments were selected to perform the experiments considering their affinity with IRM commonly described in the relevant literature, such as the nickel-aluminium (Ni-Al) based investigated by Aydelotte et al. [1,2] and Beason et al. [3], the aluminiumtungsten (Al-W) based RMs assessed by Aydelotte et al. [1,2], or the tungsten-zirconium (W-Zr) based intermetallics described by Zhang et al. [4]. Furthermore, both IRM and MREs are brittle, according to the definition provided by Lemaitre et al. [5], and therefore, these materials shatter during high-velocity impacts, reacting exothermically and releasing energy in the form of heat.

The ballistic and pyrophoric properties of commercial MREs with different compound compositions were investigated by Waite et al. [6]. In the study, thirty-three metals and metal alloys were assessed and compared. Cylindrical fragments were shot with velocities ranging from $300 \mathrm{~m} / \mathrm{s}$ to $1600 \mathrm{~m} / \mathrm{s}$. The targets were $1.27 \mathrm{~mm}$ thick 7075-T6 aluminium plates (HB 150), $1.6 \mathrm{~mm}$ thick titanium plates (HB 145) and $1.8 \mathrm{~mm}$ thick 1010 steel (HB 100). All the MREs mixtures assessed showed IIER, recording temperatures ranging from $2300{ }^{\circ} \mathrm{C}$ up to $3000^{\circ} \mathrm{C}[6]$.

Similar observations were described by Hillstrom [7], who assessed the ignition threshold for cylindrical fragments of MREs impacting $6.35 \mathrm{~mm}$ thick aluminium targets (HB 120) and $38 \mathrm{~mm}$ thick steel blocks (HB 140). Both Waite et al. [6] and Hillstrom [7] documented that commercial MREs showed mechanically induced pyrophoricity at lower impact velocities than other pyrophoric metals. The authors linked the IIER with the failure mechanisms observed: the pyrophoric metals tested, such as zirconium, titanium, hafnium, steel or copper, experience ductile failure and mechanical induced ignition from the frictional stresses caused by the target/penetrator interaction. On the other hand, the ignition mechanism for the MREs samples was attributed to internal shear stresses producing intergranular friction and heating.

Furthermore, Hillstrom [7] noted that the thickness and material of the target influenced the IIER for MREs. The different mechanical properties involved in the fragment/plate interaction affected the values of impulsive load applied to the fragment, influencing the shattering and reaction.

Aydelotte et al. [1,2] and Beason et al. [3], among others, linked impact-induced fracture of IRM to IIER. In the case of MREs, an oxide reduction is responsible for the IIER, while the reaction experienced by IRM is an intermetallic formation reaction, manifesting as heat release rather than pressure rise, as Aydelotte [1] and Cagle [8] observed. However, even considering the significantly different nature of the reactions, the macroscopic effects of IIER are considerably similar, and peak temperatures are in the same range. Therefore, MREs fragments represent a valid selection for the investigation of IIER during HVIs. In addition, the commercial availability and relative cost-effectiveness make MREs a sensible choice for the study.

The works from Waite et al. [6] and Hillstrom [7] represent a valid reference in assessing the ballistic and pyrophoric investigation of MREs. The present work discusses the IIER of MREs using a state-of-the-art experimental set-up, described in detail in Section 2.1. 
Furthermore, the HVI of MREs described in this paper were performed using armour steel plates with HB hardness significantly higher than targets used in previous studies, as they are representative of a realistic target in a modern warfare scenario.

The experimental outcomes were quantified in terms of Critical Impact Velocities $(C I V)$, Critical Kinetic Energy $\left(\mathrm{E}_{\text {kin crit }}\right)$, Specific Kinetic Energy $\left(E_{\text {Kin crit }}^{\text {Specific }}\right)$ and normalised $\mathrm{E}_{\text {Kin crit }}\left(\widetilde{E}_{\text {kin }}^{\text {crit }}\right)$. Prior to the quantitative analysis of the HVI outcomes, the influence of the impact pitch angle $(\alpha)$ on the perforation process was investigated to define a threshold value for $\alpha$. Details are discussed in Section 2.2.

The development of an energy-based model is exposed in Sections 2.3 and 4.

The investigation of the IIER is discussed in Section 3.4.

\section{Materials and Methods}

HVI experiments of MRE fragments impacting armour steel plates were performed using a $7.62 \mathrm{~mm}$ calibre powder gun. The set-up allows the fragments to reach velocities up to $1600 \mathrm{~m} / \mathrm{s}$. A double infrared (IR) light barrier LS 260 was employed as impact velocity measurement system for the fragments before the impact. The IR were $0.5 \mathrm{~m}$ apart and can capture velocities up to $2000 \mathrm{~m} / \mathrm{s}$. A Shimadzu HPV-1 high-speed camera, triggered by the IR system, records the shots. The target is installed inside a closed ballistic chamber, equipped with a window allowing high-speed recording.

Among the parameters affecting the fragment/plate interaction, the impact pitch angle $(\alpha)$, defined as the angle formed between the longitudinal axis of the fragment and the horizontal flight direction, plays a crucial role, as discussed by Zukas [9] and Rosenberg et al. [10]. The experimental set-up, shown schematically in Figure 2, enables measuring $\alpha$ but does not allow the measurement of the yaw angle, i.e., the angle between the longitudinal axis of the fragment and the vertical reference plane, nor any rolling rotation.

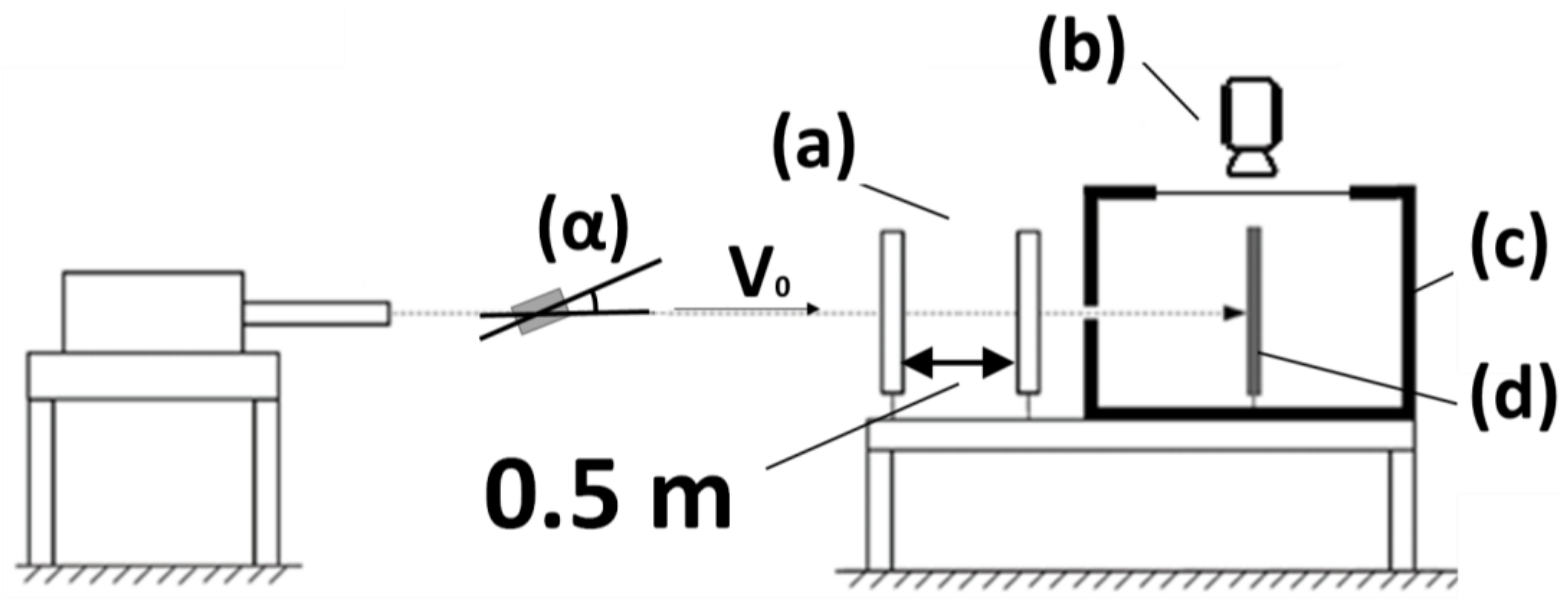

Figure 2. Ballistic experiment schematic set-up: (a) light barrier; (b) high-speed camera; (c) ballistic chamber; (d) target; $(\alpha)$ impact-pitch angle.

By analyzing the high-speed recordings it was possible measuring the residual velocities $\left(v_{\text {res }}\right)$ reached by the shattered fragments behind the target after perforation, by the plugs ejected from the plate after the perforation, and by the energy release front. The evaluation of $v_{\text {res }}$ was performed by measuring the component of the velocity vector normal to the target, as indicated in Figure 3.

The effects of $\alpha$ were quantified by measuring the significant variations in $v_{\text {res }}$, using as reference a $10 \mathrm{~mm} \times 10 \mathrm{~mm}$ grid placed on the background of the ballistic chamber: the grid as allows estimating the distance travelled in a specific timeframe. The recordings were performed at a frame rate of 250,000 fps. 

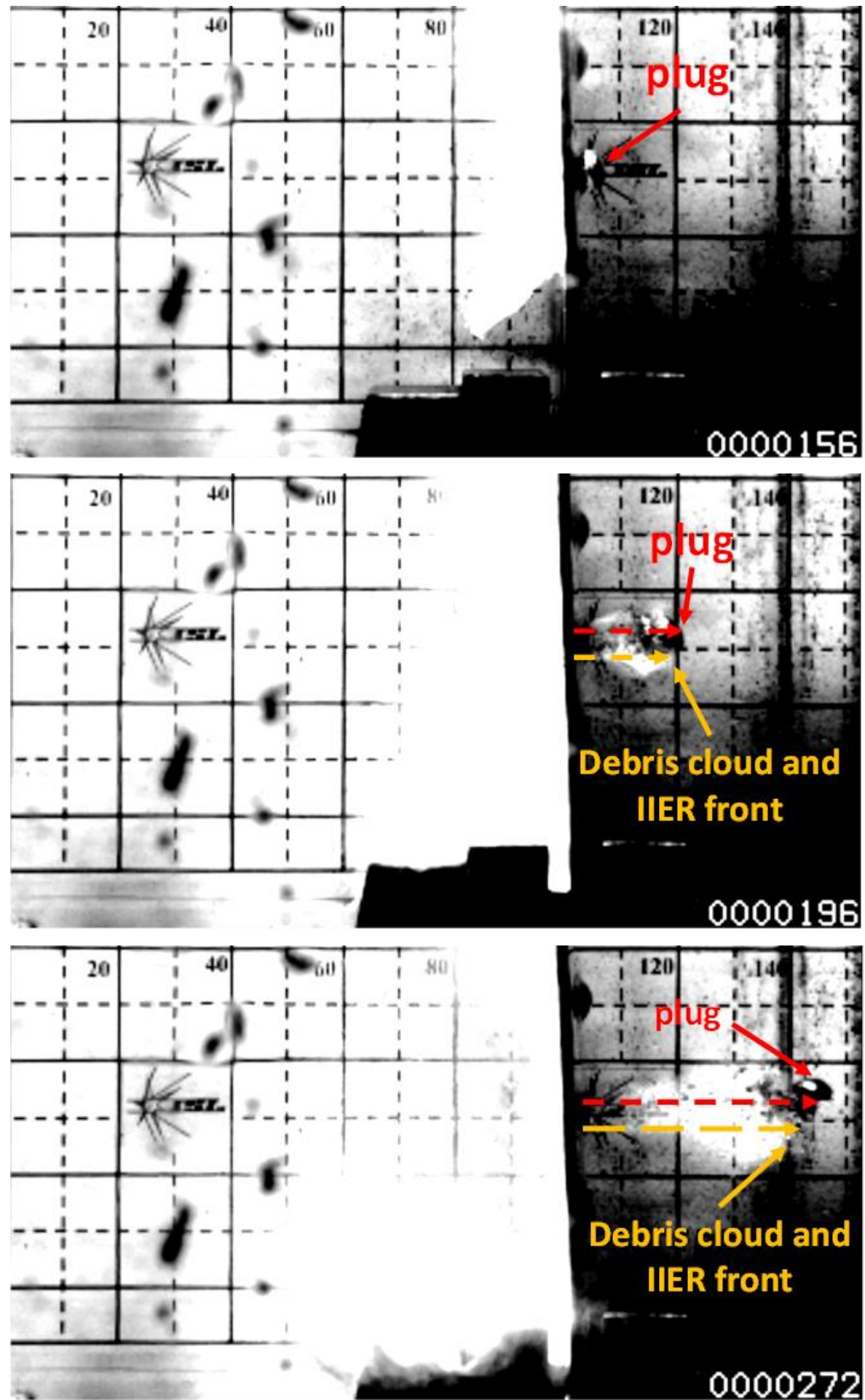

Figure 3. $5 \mathrm{~mm}$ MRE fragment impacting $2 \mathrm{~mm}$ plate at $889 \mathrm{~m} / \mathrm{s}$. Estimated residual velocity of $325 \mathrm{~m} / \mathrm{s}$.

For reference, Figure 3 shows 3 frames from the high speed recordings of a $5 \mathrm{~mm}$ MRE fragment impacting a $2 \mathrm{~mm}$ plate at $889 \mathrm{~m} / \mathrm{s}$. It is visible that the plug, the front of the debris cloud and the energy release front, travel with significantly similar residual velocities, provided the absence of intense rotations.

Five shots were performed without lighting to focus on the IIER. This set-up does not allow evaluating the angle of impact $\alpha$ but is necessary to focus on reaction initiation and evolution. 


\subsection{Materials}

Mixed Rare Earths (MRE) are commercially available pyrophoric mixtures. The compound used in the experiments is composed mainly of cerium (Ce, $49 \%)$ and lanthanum (La, 23\%). A detailed list of the components of commercially available MRE from different suppliers is available [11].

Table 1 lists the mechanical properties of MRE and armour steel used in this paper.

Table 1. Mechanical properties of MRE [6] and armour steel.

\begin{tabular}{ccccc}
\hline Material & E (GPa) & Yield Str. (MPa) & Ult. Str. (MPa) & $\rho\left(\mathbf{g} / \mathbf{c m}^{\mathbf{3}}\right)$ \\
\hline MRE & $15.9 \div 31.7$ & $96.5 \div 126.3$ & $128.9 \div 159.3$ & 6.35 \\
\hline Armour steel & 210 & 1050 & 1150 & 7.50 \\
\hline
\end{tabular}

A total of 94 cylindrical fragments were used to perform the analyses. The fragments can be divided into three categories: MRE samples with a diameter of $5 \mathrm{~mm}$, MRE samples with a diameter of $3.5 \mathrm{~mm}$, and steel fragments with a diameter of $4.6 \mathrm{~mm}$. All fragments had a length $(L)$ over diameter $(d)$ ratio $(L / d)$ of one. The masses of the MRE fragments are 0.6 and $0.2 \mathrm{~g}$, respectively, while the steel fragments weigh $0.6 \mathrm{~g}$. The fragments were encapsulated in a plastic sabot, which in turn was fixed on a $7.62 \mathrm{~mm}$ cartridge. The shooting velocities were controlled by adjusting the amount of gun powder used to fill the cartridge. During the flight, the fragment separates from the sabot due to the different kinetic energies.

Similarly to what described by Waite et al. [6] and Hillstrom [7], steel fragments were used in the study. Different solutions were evaluated to achieve high comparability between shots involving fragments made from different materials. In the first approach, the geometrical features and masses were kept constant. In this manner, the experiments had the same initial kinetic energy and the same impact surface. In order to achieve this, considering the different densities of the materials, a hole was drilled on the back end of steel cylinders with diameters of $5 \mathrm{~mm}$ and $\mathrm{L} / \mathrm{d}$ ratio of one to reduce the mass to the desired value. However, this solution was discarded as it influenced the deformation and failure of the fragments significantly. Consequently, an agreement was made to keep the mass of the fragments constant, keeping the $L / d$ ratio fixed to one. Therefore, the diameter of the steel fragments was decreased to $4.6 \mathrm{~mm}$ steel fragments obtaining a mass of 0.6 . Armour steel plates with three different thicknesses $(2 \mathrm{~mm}, 2.5 \mathrm{~mm}$ and $3 \mathrm{~mm})$ were used in the experiments. Figure 4 shows a $10 \mathrm{~mm} \times 10 \mathrm{~mm} \times 2 \mathrm{~mm}$ plate and the different fragments employed.

\subsection{Influence of Impact Pitch Angle ( $\alpha$ ) on HVIs}

The impact pitch angle $(\alpha)$ plays a crucial role on impacts, as discussed by Zukas [9] and Rosenberg et al. [10]. However, Zukas [9] highlighted that the influence of $\alpha$ is inhibited when materials with significantly different hardness values interact, as in the case of rigid penetrators impacting a relatively soft target. Similarly, the hardness of the plates used in the experiments described is up to three times $(270 \div 380 \mathrm{HB})$ the hardness of the MRE fragments $(120 \mathrm{HB})$. Therefore, the influence of $\alpha$ on the experimental outcomes needed to be quantified. An analysis of the $v_{\text {res }}$ of the plugs recorded for $5 \mathrm{~mm}$ MRE fragments impacting $2 \mathrm{~mm}$ plates was performed to quantify the threshold value of $\alpha$.

The Recht-Ipson (RI) [12] formula, shown in Equation (1), was used to fit the experimental data

$$
v_{\text {res }}=a *\left(v_{i}^{b}-C I V^{b}\right)^{\frac{1}{b}}
$$

where $a$ and $b$ are fitting parameters. 

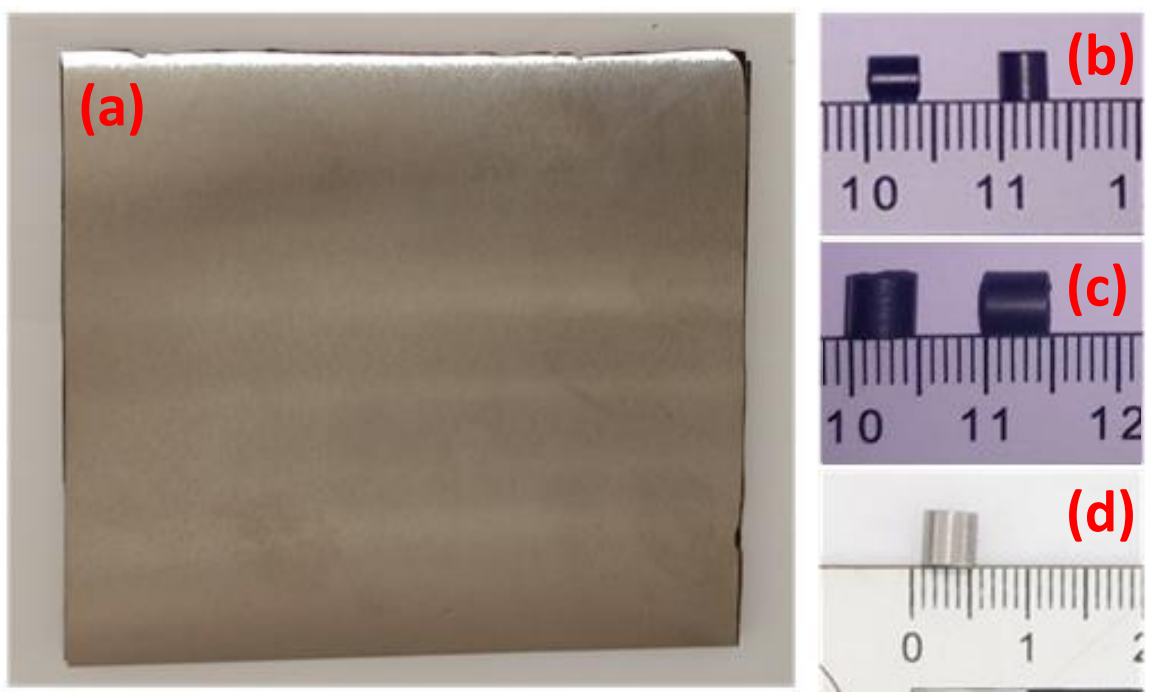

Figure 4. (a) $10 \mathrm{~mm} \times 10 \mathrm{~mm} \times 2 \mathrm{~mm}$ armour steel plate; (b) $3.5 \mathrm{~mm}$ MRE fragments; (c) $5 \mathrm{~mm}$ MRE fragments; (d) $4.6 \mathrm{~mm}$ steel fragment.

The CIV indicates the perforation capabilities of a fragment. CIV was defined as the statistically determined minimum velocity necessary to perforate a particular target with a specific fragment, with no residual velocity detected. The definition of perforation is central in this context: for our purpose, a complete perforation is considered when a plug is entirely detached from the plate, and IIER is clearly visible in the form of a reaction spreading behind the target. The $C I V$ is evaluated summing the four highest impact velocities for shots that result in no complete perforation to the four lowest impact velocities resulting in complete perforation of the target, dividing the result by the total number of shots considered, as expressed in Equation (2)

$$
C I V=\sum_{i=1}^{n} \frac{v_{i}^{\text {perf }}+v_{i}^{\text {non perf }}}{2 n}
$$

where $v_{i}^{\text {perf }}$ represents the $i^{\text {th }}$ shot resulting in perforation and $v_{i}^{\text {non }}$ perf represents the $i^{\text {th }}$ shot resulting in no perforation of the plate; $2 n$ represents the total number of shots used to evaluate the $C I V$, which in this work is 8 .

The Least Square Method was used to perform the curve fitting. It was observed that, for values of $\alpha$ lower than $30^{\circ}$ degrees, the effects on residual velocities do not influence the RI curve fit, as visible in Figure 5. It was also observed that higher values of $\alpha$ resulted in lower $v_{\text {res }}$, indicating an grater amount of energy dissipated by the target.

In the graph, the blue markers indicate the residual velocities measured for shots impacting the target with 0 degrees, the black markers indicates the residual velocities for impacts at $\alpha$ up to $30^{\circ}$ degrees, and the red markers indicate impacts at values of $\alpha$ higher than $30^{\circ}$ degrees. A significant effect in the outcomes is evident on the red markers.

The RI curves depicted in Figure 5 were defined by fitting the different dataset represented in the graph. In particular, the blue curve was obtained by fitting the residual velocities from normal impacts, the black curve from all the shots up to $30^{\circ}$ degrees, and the red curve by considering the entire data set, including shots having impact angles higher than $30^{\circ}$ degrees. The curves are sufficiently similar. However, the residual velocities indicated by the red markers are evidently lower than the value predicted by the RI curves. 


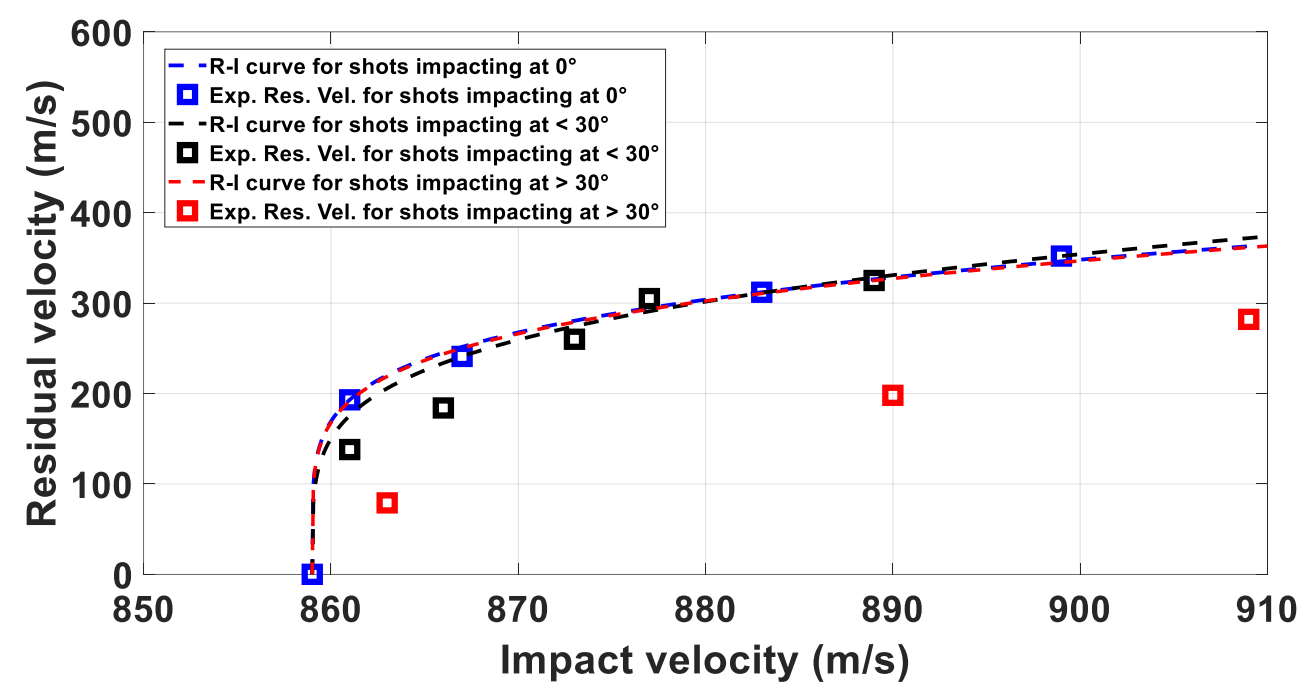

Figure 5. Recht Ipson curves for $5 \mathrm{~mm}$ fragments impacting $2 \mathrm{~mm}$ plates.

Therefore, it is reasonable to use $\alpha$ higher than $30^{\circ}$ degrees as exclusion criterion in the analytical analysis of the problem. Bratton et al. [13] described a similar threshold value for IRM impacting 4130 steel targets

\subsection{Analysis of Critical Impact Energy}

The critical impact velocity $(C I V)$, critical kinetic energy $\left(E_{\text {Kin crit }}\right)$ and residual velocity quantify the ballistic properties of HVIs of the fragments assessed. The $E_{\text {Kin crit }}$ represents the minimum kinetic energy necessary for the fragment to perforate a specific target. The $E_{\text {Kin crit }}$ is obtained by imposing the $C I V$ value as initial velocity, as described by Equation (3).

$$
E_{\text {Kin crit }}=\frac{1}{2} M V_{C I V}^{2}
$$

The analysis of the experiments described in this paper starts from the energy balance. Equation (4) expresses the energy balance formulated by Grady et al. [14], which described the HVI of cylindrical brittle fragments on steel targets.

$$
\frac{1}{2} M V_{0}^{2}=\frac{1}{2}\left(M_{\text {res }}+M_{\text {plug }}\right) v_{\text {res }}^{2}+E_{x}
$$

where $M$ is the initial mass of the fragment, $M_{\text {res }}$ and $M_{\text {plug }}$ are, respectively, the residual mass of the fragment and the mass of the plug ejected from the plate; $V_{0}$ indicates the initial velocity and $E_{x}$ was defined by Grady et al. [14] as "excess energy", which was expressed as the following sum

$$
E_{x}=E_{\text {res frg }}^{k i n}+W_{p}+E_{f}
$$

where the value $E_{\text {res }}^{\text {kin }}$ is is the residual kinetic energy associated with the expansion of the shattered fragment; $W_{p}$ is the energy dissipated by the plate in the perforation process, and $E_{f}$ is the energy absorbed by the fragment for shattering. The balance can be simplified by imposing the $C I V$ as the initial velocity in Equation (4): as result, the residual kinetic energy becomes null. Therefore, by combining Equations (3)-(5), the balance can be rewritten as follows

$$
E_{\text {Kin crit }}=\frac{1}{2} M V_{C I V}^{2}=W_{p}+E_{f}
$$

Further simplification of the balance can be made following the observations of Grady et al. [14], which remarked that the term $E_{f}$ is negligible for brittle materials, as they experience fracture without any significant plastic deformation and, therefore, without 
or with minor energy dissipation. Consequently, $E_{\text {Kin }}$ Crit can be approximated to $W_{p}$, as reported in Equation (7).

$$
E_{\text {Kin crit }}=\frac{1}{2} M V_{C I V}^{2}=W_{p}+E_{f} \cong W_{p}
$$

The quantitative evaluation of the term $W_{p}$ has been the subject of intensive study. Empirical equations for the evaluation of the term $W_{p}$ were defined in the forties by Bethe [15] and later by Taylor [16] and have been continiously improved over the years as summarised by Rosenberg et al. [10]. In this work an empirical formula, shown in Equation (8), is used for the evaluation of the term $W_{p}$

$$
W_{p}=\pi k \sigma_{u} d h^{2}
$$

where $d$ is the diameter of the fragment, $h$ is the thickness of the plate, and $\sigma_{u}$ is the ultimate stress of the plate, multiplied by the constant $k$, dependent on the strain rate. Historically, the term $k$ represented a multiplier of the strength of the plate obtained experimentally, dependent on the mechanical and geometrical features of fragments and plates involved. Recent studies such as the investigations discussed by Meyer et al. [17] and Stepanov [18] provide a physical explanation to the need of a multiplier for the ultimate strength $\sigma_{u}$ during a dynamic impact. In particular, the study performed by Meyer et al. [17] discusses the increase of yield strength observed in metals during very high strain rate loadings $\left(\dot{\varepsilon} \geq 10^{5}-10^{6} s^{-1}\right)$. Stepanov [18] also investigated the influence of strain rate of impact and explosive loading conditions on the mechanical properties of high strain steels, observing that for $\dot{\varepsilon} \geq 10^{5} \mathrm{~s}^{-1}$ the strength values exceed the static value several times. The strain rates characterising the HVI discussed in this work are estimated to be in the ranges of $4 \div 5 * 10^{5} \mathrm{~s}^{-1}$, and, therefore, the term $k$ in Dquation (8) is associated with the significant increase of yield strength experienced by the armour steel plates during the impacts. The estimated strain rate values were obtained by dividing the impact velocities by the thickness of the plate, as discussed by Cagle et al. [8]. The values obtained align with indications by Zukas [9].

By combining Equation (7) with the formula in Equation (8), the balance could be expressed as follows

$$
E_{\text {Kin crit }}=\frac{1}{2} M V_{C I V}^{2}=W_{p}+E_{f} \cong W_{p}=\pi k \sigma_{u} d h^{2}
$$

This last form of the energy balance could be rearranged through algebraic manipulation to make it adimensional, similarly to what was done by Aly et al. [19]. In the paper, seven different empirical equations valid for predicting $E_{\text {Kin crit }}$ for cylindrical and hemispherical fragments impacting metallic plates were compared. The different equations were expressed in adimensional form to identify the non-dimensional parameters affecting the normalised $E_{\text {Kin crit. }}$. It was observed that the parameter $(h / d)$, where $h$ is the plate thickness and $d$ is the diameter of the fragment, plays a critical role in evaluating the energy necessary for perforation.

Similarly to what was described by Aly et al. [19], the energy balance in Equation (9) was rewritten in adimensional form as a function of the parameter $(h / d)$

$$
\widetilde{E}_{\text {kin }}^{\text {crit }}\left(\frac{h}{d}\right)=\frac{E_{\text {Kin crit }}}{\sigma_{u} d^{3}}=\frac{W_{p}}{\sigma_{u} d^{3}}+\frac{E_{f}}{\sigma_{u} d^{3}}=\varepsilon *\left(\frac{h}{d}\right)^{2}+\varphi *\left(\frac{h}{d}\right) \cong \varepsilon *\left(\frac{h}{d}\right)^{2}
$$

where $\widetilde{E}_{\text {kin }}^{\text {crit }}$ represents the normalised $E_{\text {Kin crit. }}$. It can be observed that the parameter $\varepsilon$ represents the following expression

$$
\varepsilon=\pi * k
$$

which allows estimating the value of the multiplier $k$. 
The analytical model in Equation (10) was used to fit the $\widetilde{E}_{k i n}^{\text {crit }}$ calculated from the experimental data. The expression shows that $\widetilde{E}_{k i n}^{\text {crit }}$ is equal to a two-term quadratic equation. However, according to Grady et al. [14], the linear term is negligible in first approximation. An assessment of the validity of the approximation, the estimation of the parameters $\varepsilon$ and $\varphi$ from Equation (10) and $k$ from Equation (11) are described in Section 4.

\section{Results}

Table 2 lists the experimental outcomes for the MRE and steel fragments impacting armour steel plates with different thicknesses. The results are categorised in function of the characteristic $h / d$ parameter, where $h$ represents the plate thickness and $d$ the diameter of the fragment impacting the target. The outcomes of each shot in termos of perforation are indicated with $\mathrm{X}$ and $\mathrm{V}$ for non perforation and perforation of the targets, respectively.

Table 2. Summary of experimental results.

\begin{tabular}{|c|c|c|c|c|c|c|c|c|c|}
\hline Material & $h(\mathrm{~mm})$ & $d(\mathrm{~mm})$ & $h / d$ & Mass (g) & $\alpha^{\circ}(\mathrm{deg})$ & $\mathrm{V}_{0}(\mathrm{~m} / \mathrm{s})$ & $v_{\text {res }}(\mathrm{m} / \mathrm{s})$ & $\Delta E_{k i n}(\mathrm{~J})$ & Perforation \\
\hline \multirow{15}{*}{ MRE } & \multirow{15}{*}{2} & \multirow{15}{*}{5} & \multirow{15}{*}{0.4} & \multirow{15}{*}{0.6} & 16 & 843 & 0 & 221 & $x$ \\
\hline & & & & & 2 & 852 & 0 & 226 & $X$ \\
\hline & & & & & 22 & 857 & 184 & 141 & $\mathrm{~V}$ \\
\hline & & & & & 19 & 861 & 0 & 231 & $x$ \\
\hline & & & & & 0 & 861 & 193 & 139 & $\mathrm{~V}$ \\
\hline & & & & & 0 & 867 & 241 & 122 & $\mathrm{~V}$ \\
\hline & & & & & 0 & 870 & 0 & 236 & $x$ \\
\hline & & & & & 12 & 873 & 260 & 117 & $\mathrm{~V}$ \\
\hline & & & & & 24 & 877 & 278 & 112 & $\mathrm{~V}$ \\
\hline & & & & & 18 & 877 & 305 & 102 & $\mathrm{~V}$ \\
\hline & & & & & 0 & 883 & 312 & 102 & $\mathrm{~V}$ \\
\hline & & & & & 28 & 889 & 325 & 99 & $\mathrm{~V}$ \\
\hline & & & & & 0 & 899 & 352 & 93 & $\mathrm{~V}$ \\
\hline & & & & & 2 & 1099 & 500 & 112 & $\mathrm{~V}$ \\
\hline & & & & & 18 & 1311 & 714 & 111 & V \\
\hline \multirow{16}{*}{ MRE } & \multirow{16}{*}{2.5} & \multirow{16}{*}{5} & \multirow{16}{*}{0.5} & \multirow{16}{*}{0.6} & 0 & 883 & 0 & 243 & $x$ \\
\hline & & & & & 8 & 909 & 0 & 257 & $x$ \\
\hline & & & & & 4 & 928 & 0 & 268 & $x$ \\
\hline & & & & & 10 & 938 & 153 & 192 & $\mathrm{~V}$ \\
\hline & & & & & 7 & 960 & 0 & 287 & $x$ \\
\hline & & & & & 10 & 972 & 134 & 219 & $\mathrm{~V}$ \\
\hline & & & & & 22 & 981 & 263 & 161 & $\mathrm{~V}$ \\
\hline & & & & & 20 & 992 & 280 & 160 & $\mathrm{~V}$ \\
\hline & & & & & 20 & 1061 & 337 & 163 & $\mathrm{~V}$ \\
\hline & & & & & 2 & 1091 & 333 & 179 & $\mathrm{~V}$ \\
\hline & & & & & 20 & 1177 & 473 & 154 & $\mathrm{~V}$ \\
\hline & & & & & 28 & 1220 & 541 & 144 & $\mathrm{~V}$ \\
\hline & & & & & $\mathrm{ND}^{1}$ & 1252 & - & - & $\mathrm{V}$ \\
\hline & & & & & $\mathrm{ND}^{2}$ & 1312 & 555 & 178 & $\mathrm{~V}$ \\
\hline & & & & & $\mathrm{ND}^{2}$ & 1372 & 538 & 217 & $\mathrm{~V}$ \\
\hline & & & & & $\mathrm{ND}^{2}$ & 1427 & 625 & 200 & $\mathrm{~V}$ \\
\hline \multirow{11}{*}{ MRE } & \multirow{11}{*}{3} & \multirow{11}{*}{5} & \multirow{11}{*}{0.6} & \multirow{11}{*}{0.6} & 18 & 1035 & 0 & 334 & $x$ \\
\hline & & & & & 16 & 1043 & 0 & 339 & $x$ \\
\hline & & & & & 5 & 1051 & 0 & 344 & $x$ \\
\hline & & & & & 23 & 1060 & 0 & 350 & $x$ \\
\hline & & & & & 0 & 1075 & 103 & 294 & $\mathrm{~V}$ \\
\hline & & & & & 10 & 1085 & 214 & 236 & $\mathrm{~V}$ \\
\hline & & & & & 5 & 1099 & 172 & 268 & $\mathrm{~V}$ \\
\hline & & & & & 12 & 1141 & 245 & 250 & $\mathrm{~V}$ \\
\hline & & & & & 22 & 1366 & 416 & 281 & $\mathrm{~V}$ \\
\hline & & & & & $\mathrm{ND}^{1}$ & 1420 & 500 & 264 & $\mathrm{~V}$ \\
\hline & & & & & $\mathrm{ND}^{1}$ & 1432 & 384 & 342 & $\mathrm{~V}$ \\
\hline
\end{tabular}


Table 2. Cont.

\begin{tabular}{|c|c|c|c|c|c|c|c|c|c|}
\hline Material & $h(\mathrm{~mm})$ & $d(\mathrm{~mm})$ & $h / d$ & Mass (g) & $\alpha^{\circ}(\mathrm{deg})$ & $\mathrm{V}_{0}(\mathrm{~m} / \mathrm{s})$ & $v_{r e s}(\mathrm{~m} / \mathrm{s})$ & $\Delta E_{k i n}(\mathrm{~J})$ & Perforation \\
\hline \multirow{10}{*}{ MRE } & \multirow{10}{*}{2} & \multirow{10}{*}{3.5} & \multirow{10}{*}{0.57} & \multirow{10}{*}{0.2} & 0 & 985 & 0 & 103 & $x$ \\
\hline & & & & & 23 & 997 & 0 & 106 & $x$ \\
\hline & & & & & 0 & 1023 & 87 & 93 & V \\
\hline & & & & & 0 & 1029 & 98 & 92 & $\mathrm{~V}$ \\
\hline & & & & & 0 & 1034 & 0 & 114 & $x$ \\
\hline & & & & & 12 & 1036 & 134 & 87 & $\mathrm{~V}$ \\
\hline & & & & & 28 & 1045 & 0 & 117 & $x$ \\
\hline & & & & & 26 & 1078 & 232 & 77 & $\mathrm{~V}$ \\
\hline & & & & & 0 & 1206 & 326 & 77 & $\mathrm{~V}$ \\
\hline & & & & & 27 & 1228 & 307 & 85 & $\mathrm{~V}$ \\
\hline \multirow{10}{*}{ MRE } & \multirow{10}{*}{2.5} & \multirow{10}{*}{3.5} & \multirow{10}{*}{0.71} & \multirow{10}{*}{0.2} & 26 & 1240 & 0 & 164 & $x$ \\
\hline & & & & & 0 & 1245 & 0 & 166 & $x$ \\
\hline & & & & & 17 & 1248 & 31 & 158 & $\mathrm{~V}$ \\
\hline & & & & & 20 & 1270 & 0 & 173 & $x$ \\
\hline & & & & & 22 & 1281 & 95 & 150 & $\mathrm{~V}$ \\
\hline & & & & & 28 & 1290 & 0 & 178 & $x$ \\
\hline & & & & & 28 & 1315 & 193 & 135 & $\mathrm{~V}$ \\
\hline & & & & & 25 & 1317 & 239 & 124 & V \\
\hline & & & & & 30 & 1330 & 250 & 117 & $\mathrm{~V}$ \\
\hline & & & & & 28 & 1397 & 268 & 127 & $\mathrm{~V}$ \\
\hline \multirow{8}{*}{ MRE } & \multirow{8}{*}{3} & \multirow{8}{*}{3.5} & \multirow{8}{*}{0.86} & \multirow{8}{*}{0.2} & 3 & 1491 & 0 & 238 & $x$ \\
\hline & & & & & 19 & 1495 & 0 & 239 & $x$ \\
\hline & & & & & 8 & 1502 & 0 & 241 & $x$ \\
\hline & & & & & 6 & 1508 & 149 & 198 & $\mathrm{~V}$ \\
\hline & & & & & 15 & 1532 & 0 & 251 & $x$ \\
\hline & & & & & 29 & 1541 & 82 & 228 & $\mathrm{~V}$ \\
\hline & & & & & 28 & 1549 & 119 & 219 & $\mathrm{~V}$ \\
\hline & & & & & 7 & 1560 & 185 & 202 & $\mathrm{~V}$ \\
\hline \multirow{8}{*}{ Steel } & \multirow{8}{*}{2} & \multirow{8}{*}{4.6} & & & 0 & 550 & 0 & 91 & $x$ \\
\hline & & & & & 2 & 583 & 0 & 102 & $x$ \\
\hline & & & & & 0 & 597 & 75 & 82 & $\mathrm{~V}$ \\
\hline & & & & & 3 & 600 & 0 & 108 & $x$ \\
\hline & & & 0.43 & 0.6 & 10 & 630 & 142 & 71 & $\mathrm{~V}$ \\
\hline & & & & & 0 & 643 & 134 & 78 & $\mathrm{~V}$ \\
\hline & & & & & 5 & 656 & 0 & 129 & $x$ \\
\hline & & & & & 0 & 693 & 154 & 87 & $\mathrm{~V}$ \\
\hline & & & & & 5 & 733 & 0 & 161 & $x$ \\
\hline & & & & & 12 & 735 & 0 & 162 & $X$ \\
\hline & & & & & 5 & 771 & 91 & 139 & $\mathrm{~V}$ \\
\hline & & & & & 0 & 773 & 0 & 179 & $X$ \\
\hline Steel & 2.5 & 4.6 & 0.54 & 0.6 & 4 & 777 & 135 & 124 & $\mathrm{~V}$ \\
\hline & & & & & 0 & 785 & 174 & 112 & $\mathrm{~V}$ \\
\hline & & & & & 11 & 806 & 189 & 114 & $\mathrm{~V}$ \\
\hline & & & & & 2 & 808 & 0 & 196 & $X$ \\
\hline & & & & & 10 & 786 & 0 & 185 & $x$ \\
\hline & & & & & 3 & 806 & 104 & 148 & $\mathrm{~V}$ \\
\hline & & & & & 0 & 824 & 0 & 204 & $x$ \\
\hline & & & & & 0 & 831 & 167 & 132 & $\mathrm{~V}$ \\
\hline Steel & 3 & 4.6 & 0.65 & 0.6 & 18 & 833 & 0 & 208 & $x$ \\
\hline & & & & & 0 & 840 & 0 & 212 & $X$ \\
\hline & & & & & 8 & 852 & 176 & 137 & $\mathrm{~V}$ \\
\hline & & & & & 2 & 866 & 182 & 140 & $\mathrm{~V}$ \\
\hline
\end{tabular}

${ }^{1}$ Shot performed in the darkroom. The angle of impact and residual velocities were not quantifiable. ${ }^{2}$ Shot performed in the darkroom. The angle of impact is not quantifiable. 


\subsection{Critical Impact Velocity $(C I V)$, Critical Impact Energy $\left(E_{\text {Kin crit }}\right)$ and Normalised $E_{\text {Kin crit }}$}

Table 3 lists the $C I V$, the $E_{\text {Kin crit }}, E_{\text {Kin crit }}^{\text {Specific }}$ and the $\widetilde{E}_{\text {kin }}^{c r i t}$ defined using the shots listed in Table 2.

Table 3. Summary of results for $C I V, E_{\text {Kin crit }}$ and $\widetilde{E}_{\text {kin }}^{\text {crit }}$ evaluated from shots listed in Table 3.

\begin{tabular}{cccccc}
\hline Material & $\boldsymbol{h} / \boldsymbol{d}$ & $\boldsymbol{C I V}(\mathbf{m} / \mathbf{s})$ & $\boldsymbol{E}_{\text {Kin crit }}(\mathrm{J})$ & $\boldsymbol{E}_{\text {Kin crit }}^{\text {Specific }}(\mathbf{k J} / \mathbf{k g})$ & $\widetilde{\boldsymbol{E}}_{\text {kin }}^{\text {crit }}\left(\frac{\boldsymbol{h}}{\boldsymbol{d}}\right)$ \\
\hline \multirow{3}{*}{ MRE } & 0.4 & 859 & 222 & 370 & 1.54 \\
& 0.5 & 956 & 274 & 457 & 1.91 \\
& 0.6 & 1073 & 345 & 575 & 2.40 \\
\hline \multirow{3}{*}{ MRE } & 0.57 & 1028 & 106 & 530 & 2.15 \\
& 0.71 & 1276 & 163 & 815 & 3.30 \\
& 0.86 & 1518 & 230 & 1150 & 4.66 \\
\hline \multirow{3}{*}{ Steel } & 0.43 & 619 & 114 & 190 & 1.02 \\
& 0.54 & 773 & 179 & 298 & 1.60 \\
\hline
\end{tabular}

The data listed in Table 3 show that the CIV increases with increasing plate thickness for all the tested configuration. The CIV values for $4.6 \mathrm{~mm}$ steel fragments (yellow markers) are in the range of $20 \div 28 \%$ lower than the values obtained for $5 \mathrm{~mm} \mathrm{MRE} \mathrm{fragments}$ impacting targets with the same thickness, and in the range of $39 \div 45 \%$ lower than the values obtained for $3.5 \mathrm{~mm}$ MRE fragments impacting the same targets.

The same trend is reflected on the $E_{\text {Kin crit }}, E_{\text {Kin crit }}^{\text {Specific }}$ and the $\widetilde{E}_{k i n}^{\text {crit }}$ defined. The $E_{\text {Kin crit }}$ outcomes are plotted in Figure 6. Results for $5 \mathrm{~mm}$ MRE fragments and $4.6 \mathrm{~mm}$ steel fragments lie on the same kinetic energy curve as they possess the same mass. The $E_{\text {Kin crit }}$ values for $4.6 \mathrm{~mm}$ steel fragments (yellow markers) are lower ( $35 \div 49 \%$ ) than the values obtained for $5 \mathrm{~mm}$ MRE fragments impacting targets with the same thickness.

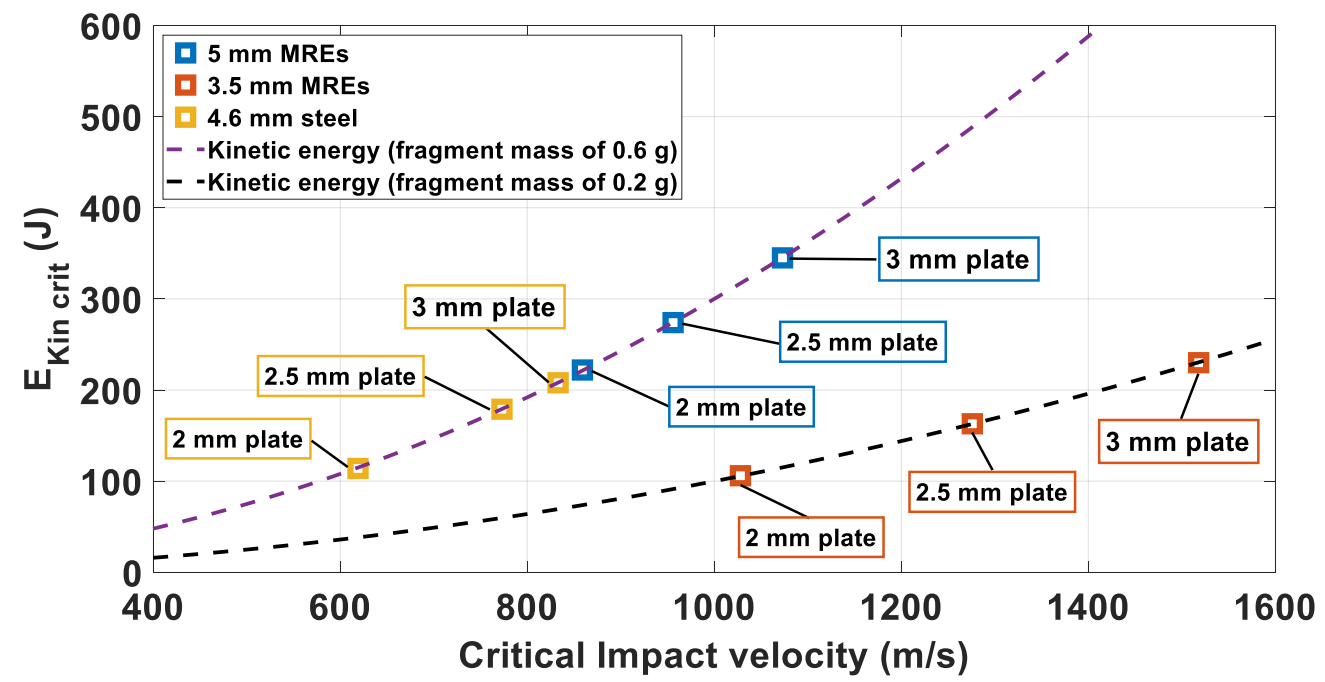

Figure 6. Critical kineti energy over critical impact velocities. The dashed lines indicate the kinetic energies for fragments having mass of 0.6 and $0.2 \mathrm{~g}$, respectively in purple and black, as function of impact velocity.

The $E_{\text {Kin crit }}$ values defined for the $3.5 \mathrm{~mm}$ MRE fragments are lower than the values obtained for $5 \mathrm{~mm}$ MRE fragments impacting the same target (52\% for $2 \mathrm{~mm}$ plates and $30 \%$ for the $3 \mathrm{~mm}$ plates).

On the othe hand, when compared with the steel fragments, the values of $E_{\text {Kin crit }}$ estimated for the $3.5 \mathrm{~mm}$ MRE fragmnets are similar, (circa $8 \%$ difference). Obviously, the fact that the $3.5 \mathrm{~mm}$ MRE fragments weigh 1/3 than the steel fragments is reflected on the $C I V$, resulting in the translation of the points along the $\mathrm{x}$ axis. 
Figure 7 shows the $E_{\text {Kin crit }}$ per unit mass for all the configurations tested. In this case, the $E_{\text {Kin crit }}^{\text {Specific }}$ values for the MRE fragments of 3.5 and $5 \mathrm{~mm}$ follow the same trend, while the values for the steel fragments are between 40 and 50\% lower.

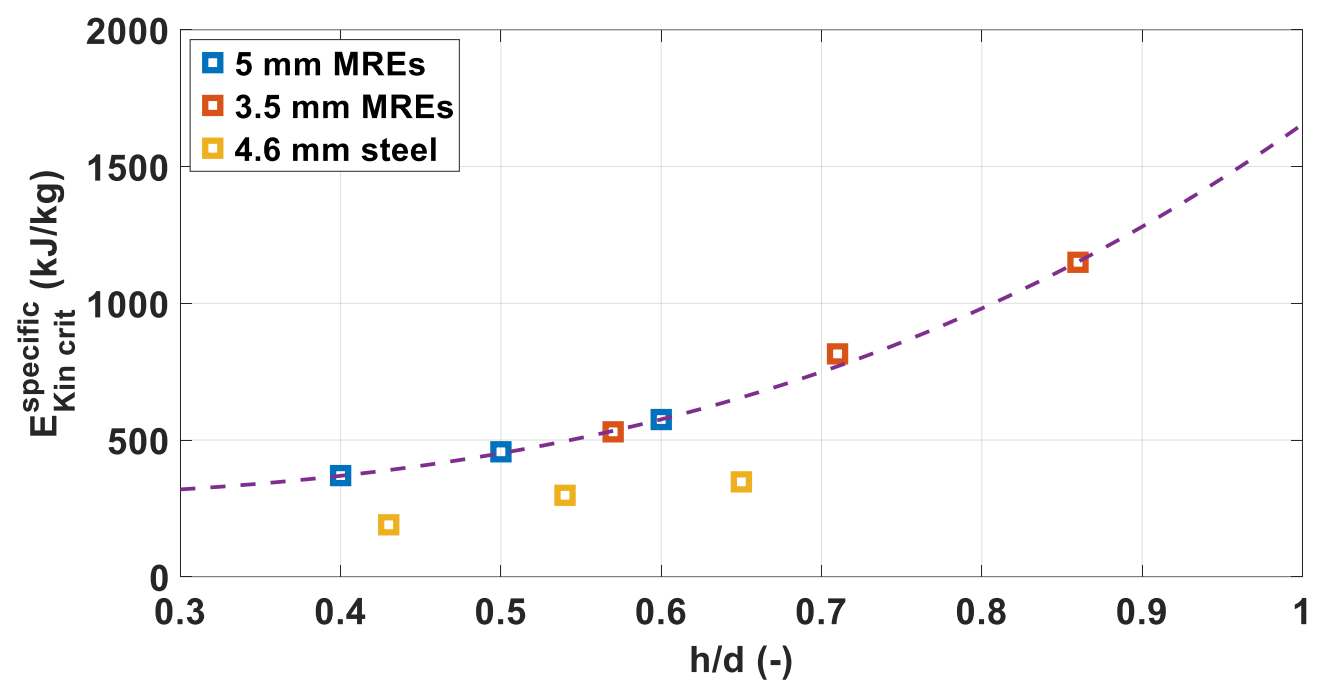

Figure 7. Specific Critical Impact Energies over normalised plate thickness. The dashed line indicates the kinetic energy per unit mass.

Furthermore, the graph indicates that the $E_{\text {Kin crit }}^{\text {Specific }}$ values observed for $3.5 \mathrm{~mm} \mathrm{MRE}$ fragments are higher than the respective values obtained for $5 \mathrm{~mm}$ fragments. The difference magnifies increasing $h / d$, going from $16 \%$ for the $2 \mathrm{~mm}$ plates to $25 \%$ for $2.5 \mathrm{~mm}$ plates and $30 \%$ for the $3 \mathrm{~mm}$ plate.

The graph in Figure 8 depicts the $\widetilde{E}_{k i n}^{c r i t}$ over $h / d$. The lower energy values obtained are linked with the different failure modes observed: MRE are brittle and undergo fragmentation upon impact, while the steel fragments are ductile and deform plastically, as visible in Figure 9. The failure mode influences significantly the fragment/plate interaction, resulting in lower impact velocities required to perforate the plates using steel fragments. This is reflected in values of $\widetilde{E}_{\text {kin }}^{c r i t}$ between 28 and $48 \%$ lower for steel fragments are than for the MRE fragments.

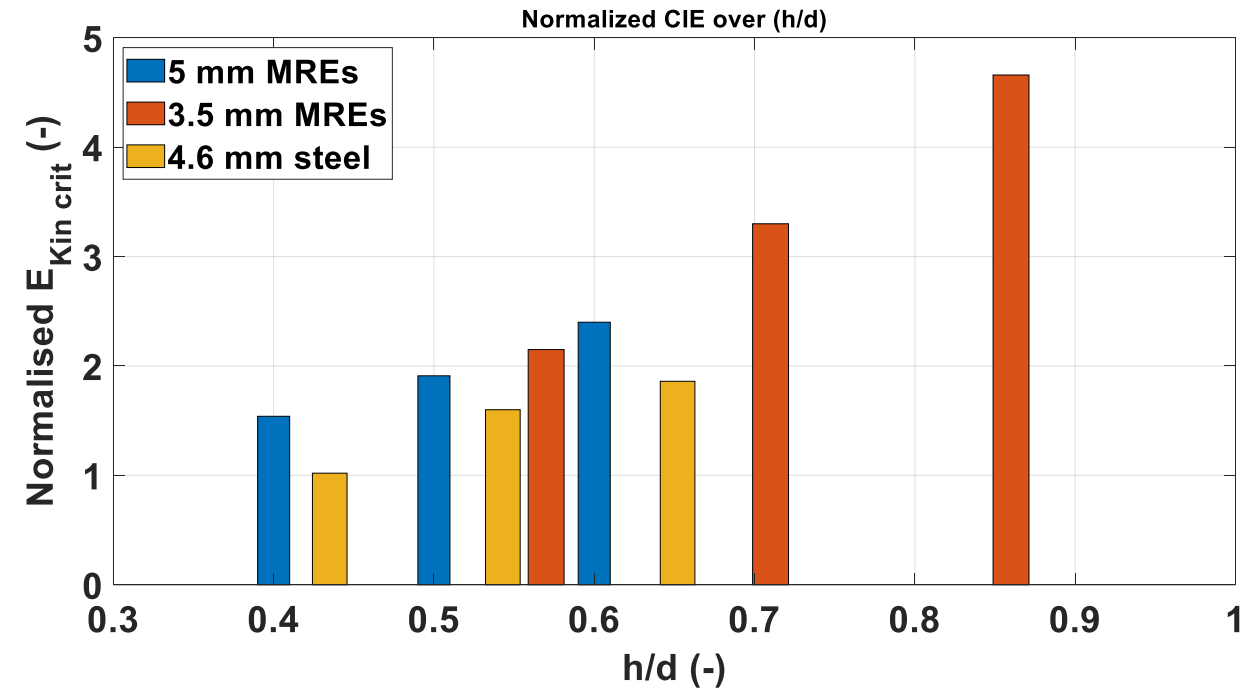

Figure 8. Plot of estimated values of $\widetilde{E}_{\text {kin }}^{c r i t}$ over normalised plate thickness. 

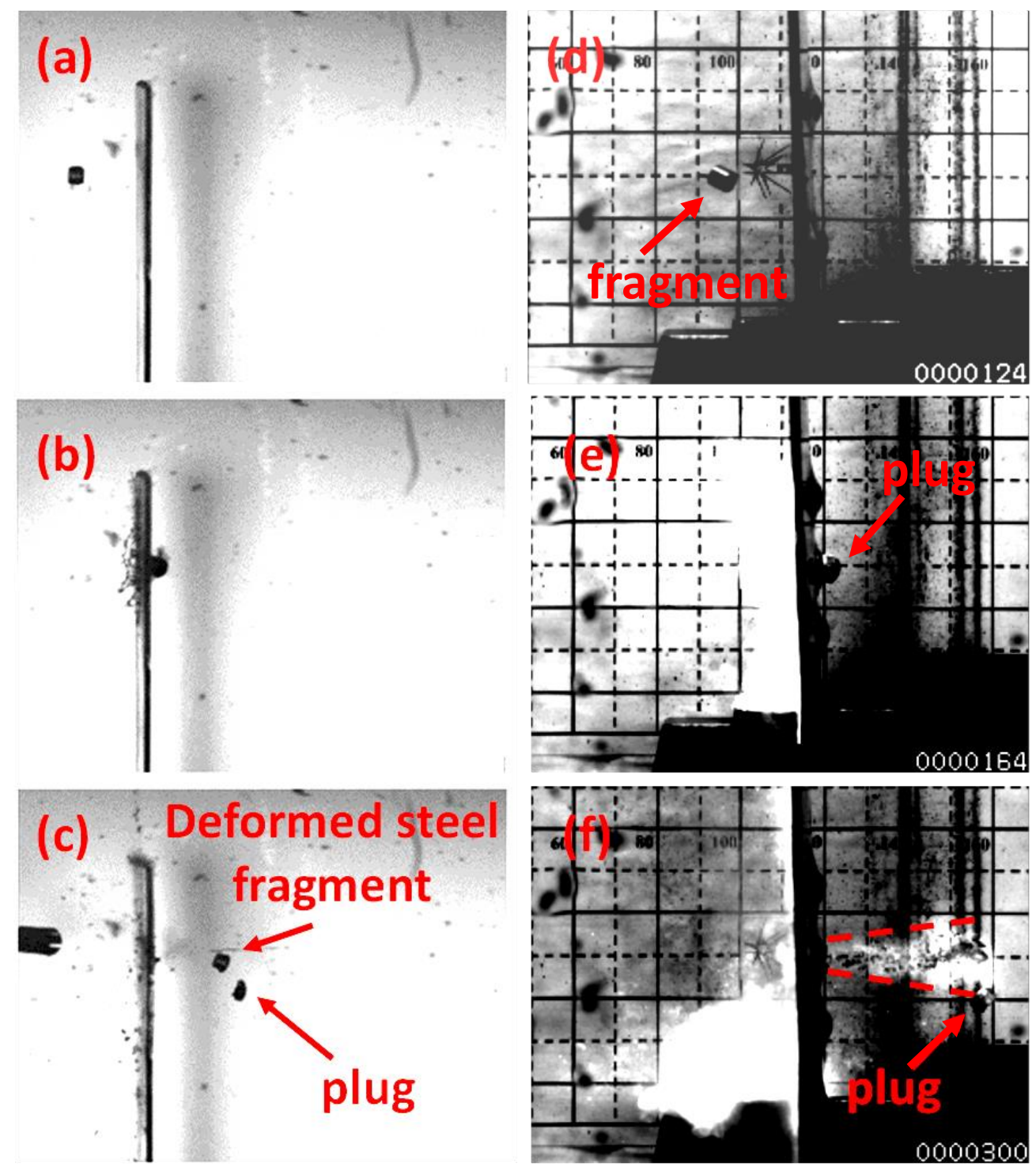

Figure 9. Failure mode comparison. On the left, $4.6 \mathrm{~mm}$ steel fragment impacting $2 \mathrm{~mm}$ plate at $693 \mathrm{~m} / \mathrm{s}$; on the right, $5 \mathrm{~mm}$ MREs fragment impacting $2 \mathrm{~mm}$ plate at $877 \mathrm{~m} / \mathrm{s}$. (a) steel fragment flying towards the target, (b) impact between steel fragment and the plate, (c) the deformed fragment perforates the target and the plug is ejected; (d) MRE fragment flying towards the target with 24 degrees of yaw, (e) impact, pre-perforation energy release and plug formation, (f) the fragment shatters during the interaction with the target and spreads behind the plate.

The frames in Figure 9 compare the time evolution of two impacts involving, on the left, a $4.6 \mathrm{~mm}$ steel fragment impacting a $2 \mathrm{~mm}$ plate at $693 \mathrm{~m} / \mathrm{s}$, and, on the right, a $5 \mathrm{~mm}$ MRE fragment impacting a $2 \mathrm{~mm}$ plate at $877 \mathrm{~m} / \mathrm{s}$.

Figure 9c displays the deformed steel fragment, having the characteristic "mushroom" shape. Figure 9f, on the other hand, shows the shattered MRE fragment and IIER. This brittle nature of MRE leads to fragmentation even at low impact velocities. The impact loadings cause intense stresses and internal friction, resulting in fragmentation and energy release. The shattered MRE fragment continues its trajectory behind the perforated plate while expanding as a debris cloud, essentially following the launch trajectory.

The high-speed recordings showed that the shattered parts of the fragment travel with comparable residual velocities of the plugs, provided the absence of rotations observed for impact velocities close to CIV. It was not possible to recover the shattered fragment as, continuing its trajectory, it further reacted, impacting walls of the chamber. 
IIER was observed in the form of light emission for all experiments involving MRE. Figure $9 f$ shows the energy release spreading. It can be observed that the energy release front travels with the same velocities of the shattered fragment and the plug.

\subsection{Plate Perforation}

The primary failure mode observed for the targets impacted at velocities above the $C I V$ was shear plugging for both the $3.5 \mathrm{~mm}$ and the $5 \mathrm{~mm}$ MRE fragments, as can be onserved in Figure 10. Shear plugging is the typical failure mode for materials with high strength and high failure strains, such as armour steel, as discussed by Hazell [16] for instance, who concluded that plugging is more favourable than plate deformation.
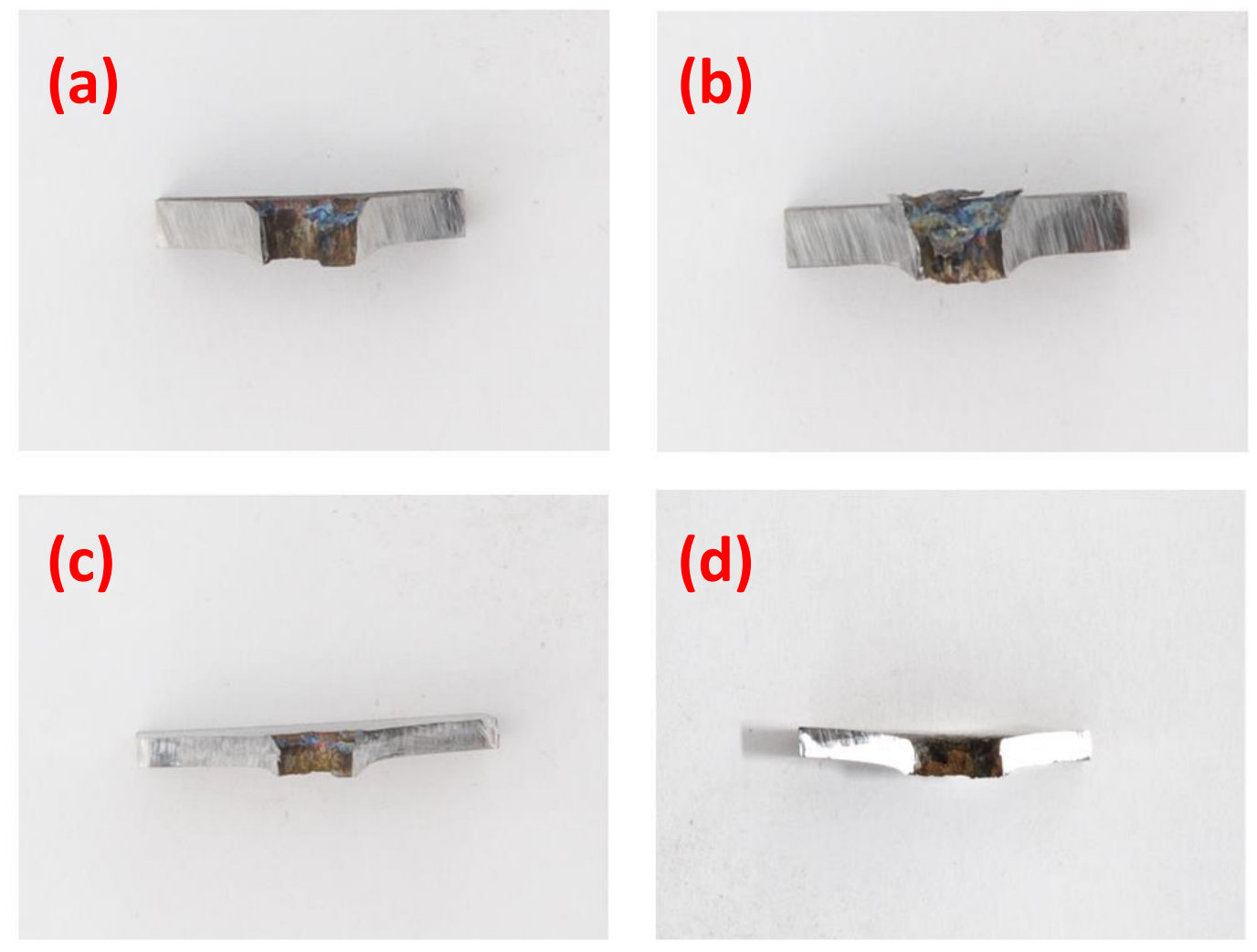

Figure 10. Cross sections of perforated plates. In detail: (a) $3 \mathrm{~mm}$ plate impacted by $5 \mathrm{~mm}$ fragment at $1075 \mathrm{~m} / \mathrm{s}$; (b) $3 \mathrm{~mm}$ plate impacted by $3.5 \mathrm{~mm}$ fragment at $1549 \mathrm{~m} / \mathrm{s}$; (c) $2 \mathrm{~mm}$ plate impacted by $5 \mathrm{~mm}$ fragment at $861 \mathrm{~m} / \mathrm{s}$; (d) $2 \mathrm{~mm}$ plate impacted by $3.5 \mathrm{~mm}$ fragment at $1023 \mathrm{~m} / \mathrm{s}$.

The cross-sections of the plates show that the perforation channels have diameters equal to the diameter of the impacting fragments. In the case of thicker plates, shown in Figure 10a,b, minor hole enlargement on the impact surface was observed.

In Figure 10c,d, some minor dishing was observed in $2 \mathrm{~mm}$ plates impacted by both the $3.5 \mathrm{~mm}$ and $5 \mathrm{~mm}$ MRE fragments at velocities close to the CIV.

The failure mode of the plate influences directly the perforation process and, consequently, the post-perforation IIER spread behind the plate. Details on the IIER velocity will be discussed in detail in Sections 3.3 and 3.4.

\subsection{Residual Velocity Analysis}

The RI curves for the experimental results were determined. Quantitative considerations are discussed for the firings involving the $5 \mathrm{~mm}$ MRE fragemnts, as the experimental setup does not allow to reach velocities greater than $1600 \mathrm{~m} / \mathrm{s}$.

In the case of $3.5 \mathrm{~mm}$ MRE fragments, it was observed that, due to the bluff shape and the mass of only $0.2 \mathrm{~g}$, the flight stability of was severely affected for velocities higher 
than $1200 \mathrm{~m} / \mathrm{s}$, and, therefore, the data collected are not sufficient for a reliable curve fit, as observable in Figure 11.

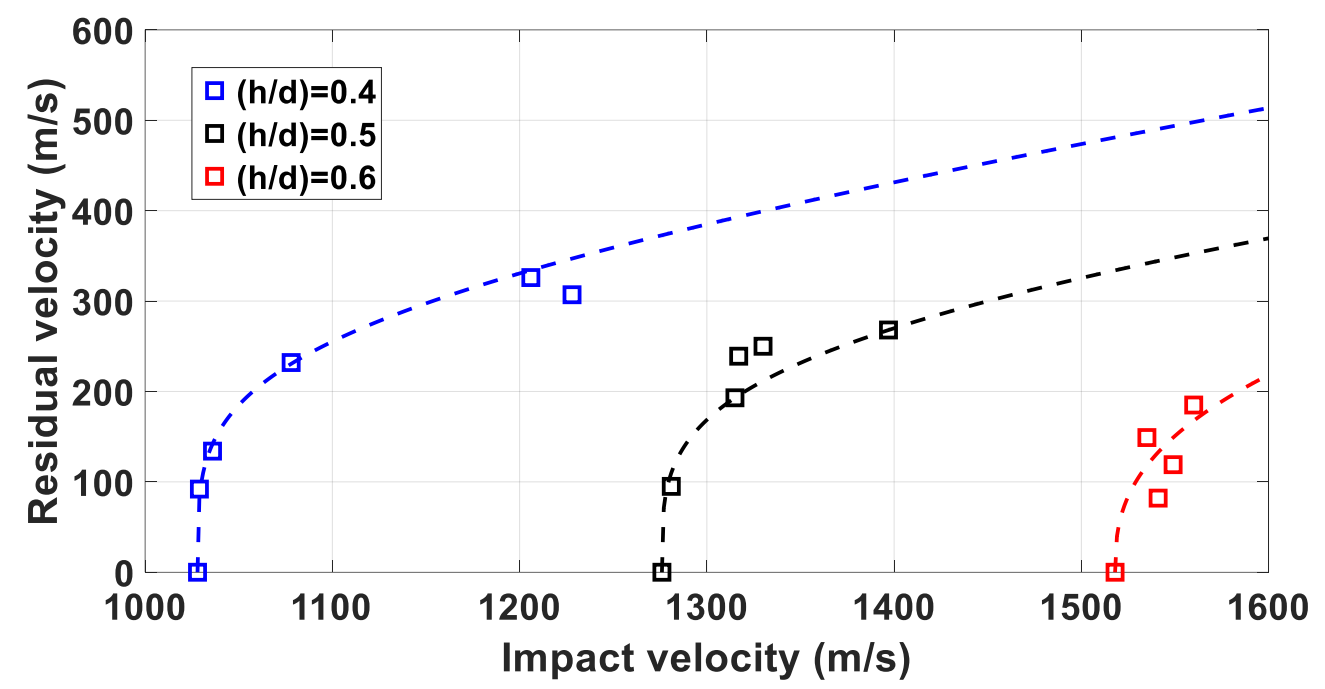

Figure 11. Recht Ipson curve fittings for $3.5 \mathrm{~mm}$ fragments: the blue markers indicate residual velocities observed impacting $2 \mathrm{~mm}$ plates; the black markers indicate residual velocities measured impacting $2.5 \mathrm{~mm}$ plates and the red markers indicate residual velocities recorded impacting $3 \mathrm{~mm}$ plates.

The results from Table 4 are plotted in Figure 12. The RI fitting coefficients $a$ and $b$ are defined for each case through a least square fit of the experimental data.

Table 4. Summary of parameters for the RI equation.

\begin{tabular}{cccc}
\hline$(\boldsymbol{h} / \boldsymbol{d})$ & $\mathrm{CIV}(\mathbf{m} / \mathbf{s})$ & $\boldsymbol{a}$ & $\boldsymbol{b}$ \\
\hline $\mathbf{0 . 4 0}$ & 859 & 0.5358 & 4.642 \\
\hline $\mathbf{0 . 5 0}$ & 956 & 0.4713 & 3.473 \\
\hline $\mathbf{0 . 6 0}$ & 1073 & 0.3712 & 3.166 \\
\hline
\end{tabular}

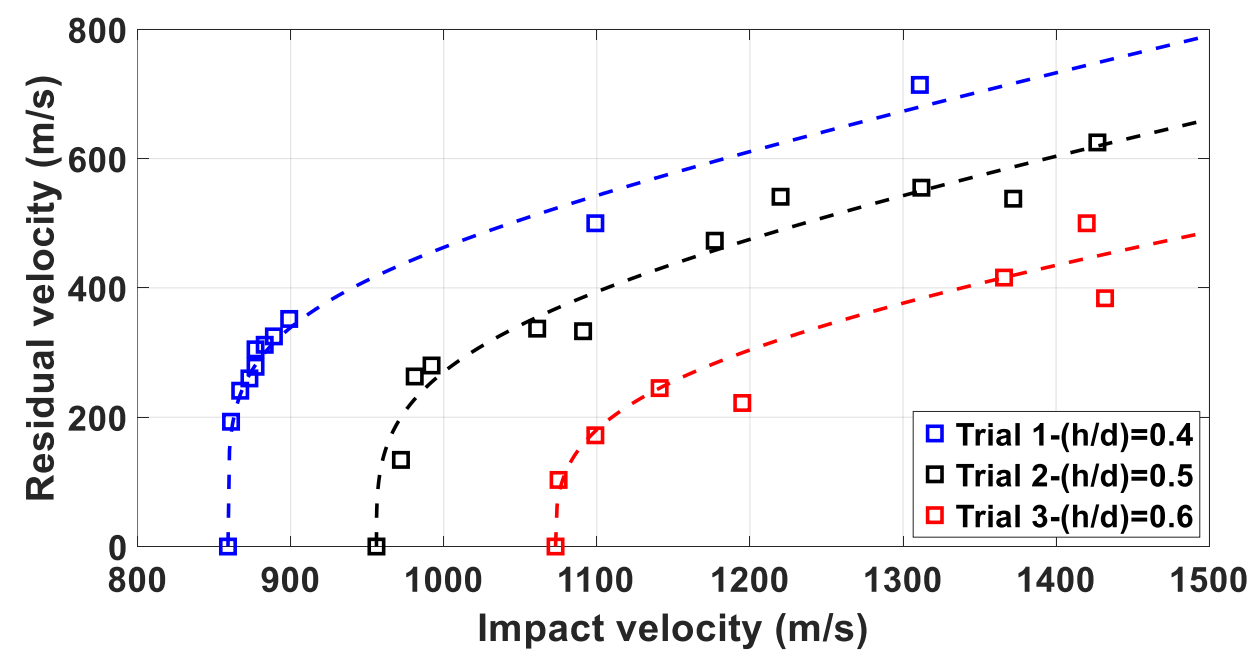

Figure 12. Recht Ipson curve fittings for $5 \mathrm{~mm}$ fragments impacting targets with values of $\alpha$ lower than $30^{\circ}$.

The RI curves indicate that the increase of thickness of the plates from $2 \mathrm{~mm}$ to $2.5 \mathrm{~mm}$ results in residual velocities circa $20 \%$ lower, while the increase from $2.5 \mathrm{~mm}$ to $3 \mathrm{~mm}$ plates 
results in a decrease of circa $30 \%$, indicating an average increase of $5 \%$ in velocity loss per additional millimetre.

Figure 13 shows the kinetic energy loss relative to the shots depicted in Figure 12. The experimental distributions depicted in Figure 13 follow a linear trend for each fragment/plate combination, as highlighted by the curve fit indicating an increase of circa $10 \%$ in terms of kinetic energy loss with increasing plate thickness by $5 \mathrm{~mm}$, i.e., $2 \%$ circa per additional millimetre.

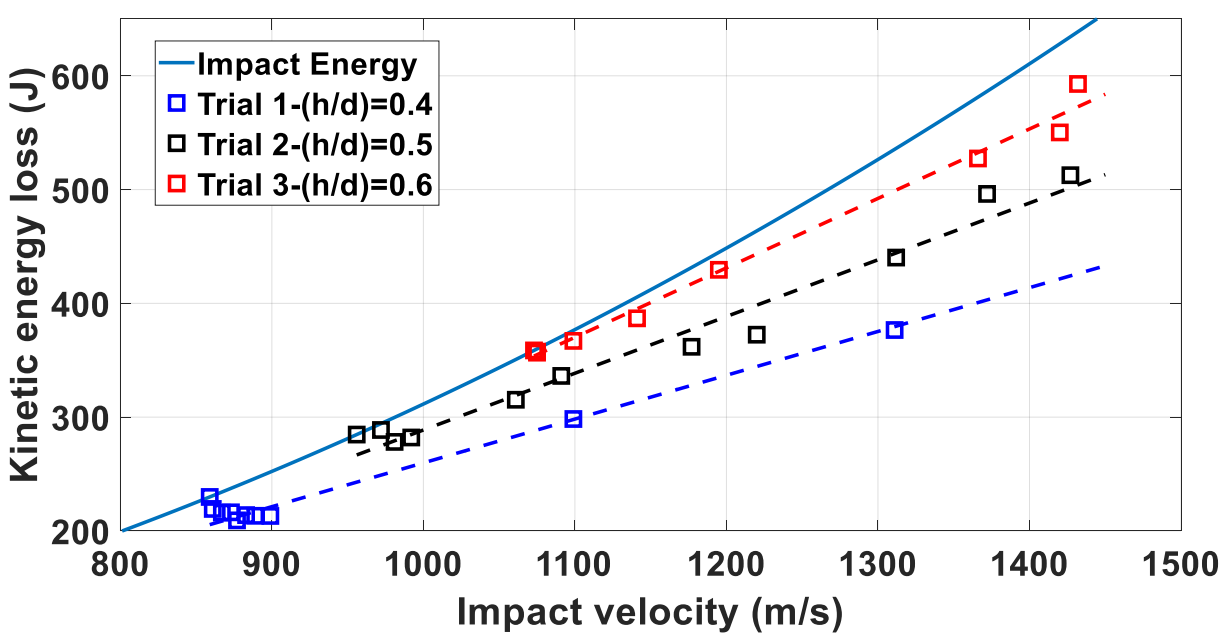

Figure 13. Kinetic energy loss for $5 \mathrm{~mm}$ fragments over impact velocity. The blue markers indicate the amout of kinetic energy lost impacting $2 \mathrm{~mm}$ plates; the black markers indicate the kinetic energy loss observed when impacting $2.5 \mathrm{~mm}$ plates and the red markers indicate the kinetic energy loss measured impacting $3 \mathrm{~mm}$ plates. The dashed lines are linear curve fit obtained from the experimental data.

\subsection{Impact Induced Energy Release}

The experimental set-up used to record the IIER did not allow to measure the impact angles for shots reported in Table 5. However, the residual velocities recorded are coherent with the analyses discussed in this paper.

Table 5. Summary of parameters for the RI equation.

\begin{tabular}{ccccc}
\hline h/d & Shot & CIV $(\mathbf{m} / \mathbf{s})$ & $\boldsymbol{v}_{\text {res plug }}(\mathbf{m} / \mathbf{s})$ & $\boldsymbol{v}_{\text {energy release front }}(\mathbf{m} / \mathbf{s})$ \\
\hline \multirow{2}{*}{0.5} & 14 & 1312 & 555 & 555 \\
& 15 & 1372 & 538 & 538 \\
& 16 & 1427 & 625 & 625 \\
\hline \multirow{2}{*}{0.6} & 10 & 1420 & 500 & 500 \\
& 11 & 1432 & 384 & 416 \\
\hline
\end{tabular}

The evaluation of the energy release front velocities, summarised in Table 5 shows that the energy release travels with velocities comparable to the residual velocities of shattered fragments and plugs flying without tumbling, as shown in Figure 3.

A visual comparison of firings involving $5 \mathrm{~mm}$ MRE fragments impacting $2.5 \mathrm{~mm}$ target at velocities of $1252 \mathrm{~m} / \mathrm{s}$ and $1220 \mathrm{~m} / \mathrm{s}$ are depicted in Figure 14, respectively, on the left and the right. The frames are taken with the same time intervals. 

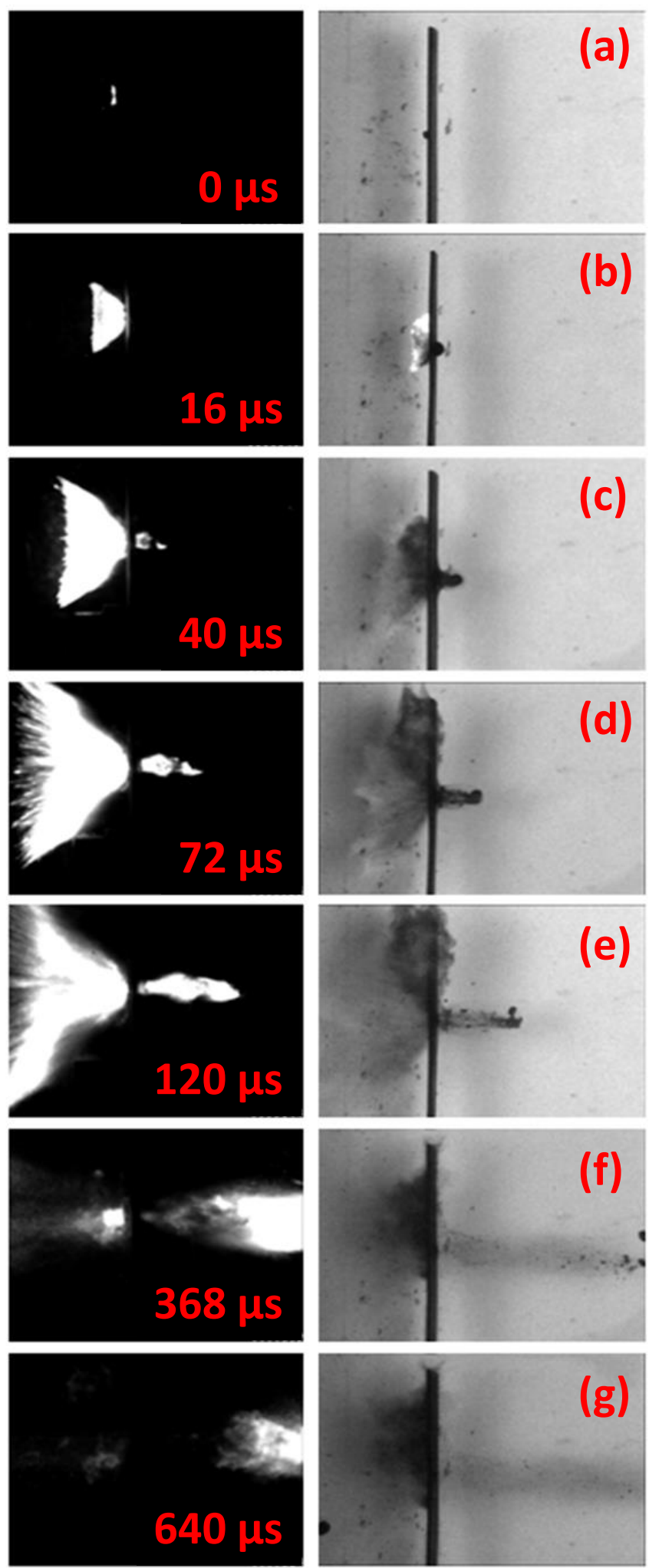

Figure 14. Time evolution of high-velocity impact for $5 \mathrm{~mm}$ MRE fragments impacting $2.5 \mathrm{~mm}$ plates. Left: energy release at impact velocity $1252 \mathrm{~m} / \mathrm{s}$. Right: impact velocity $1220 \mathrm{~m} / \mathrm{s}$. (a) impact between fragment and target, (b) interaction between the fragments and the targets and plug formation; (c) plug ejection; $(\mathbf{d}-\mathbf{g})$ plug flight behind the plate, debris cloud spreading and post-perforation energy release evolution. 
The velocity difference between the two shots is $2.5 \%$, which is sufficiently close for a qualitative discussion.

The frames on the left, recorded in a dark room, highlight the IIER time evolution, while the frames on the right show the mechanical aspects of plate perforation and MRE fragment shattering.

In Figure $14 \mathrm{a}$, the first reaction is triggered upon impact. The process continues and lasts approximately $30 \mu$ s until the plug is ejected from the target and the energy release is visible behind the target, as indicated in Figure 14c. In Figure $14 \mathrm{~d}-\mathrm{f}$ he energy release continues spreading behind the plate, mainly following a normal direction. The post-perforation energy release lasts approximatively $600 \mu \mathrm{s}$, as indicated by Figure $14 \mathrm{~g}$.

A significant amount of energy release is observed prior to perforation. During the perforation, the MRE samples are shattered into numerous smaller parts, as visible in Figure 14e,f. The reaction continues spreading and expands, following a conical shape.

\section{Discussion}

Figure 15 displays the values of $\widetilde{E}_{k i n}^{\text {crit }}$ derived from the experimental results for each fragment-plate combination over the $h / d$ parameter. The trend shown by the experimental $\widetilde{E}_{k i n}^{\text {crit }}$ values in follow the same tendency observed by Børvik [20] and Wen [21] in their papers describing the transition zone between shear plugging and adiabatic shear plugging. In both publications, the transition zone between plugging failure modes was identified for values of $h / d$ ranging between 0.5 and 0.6 .

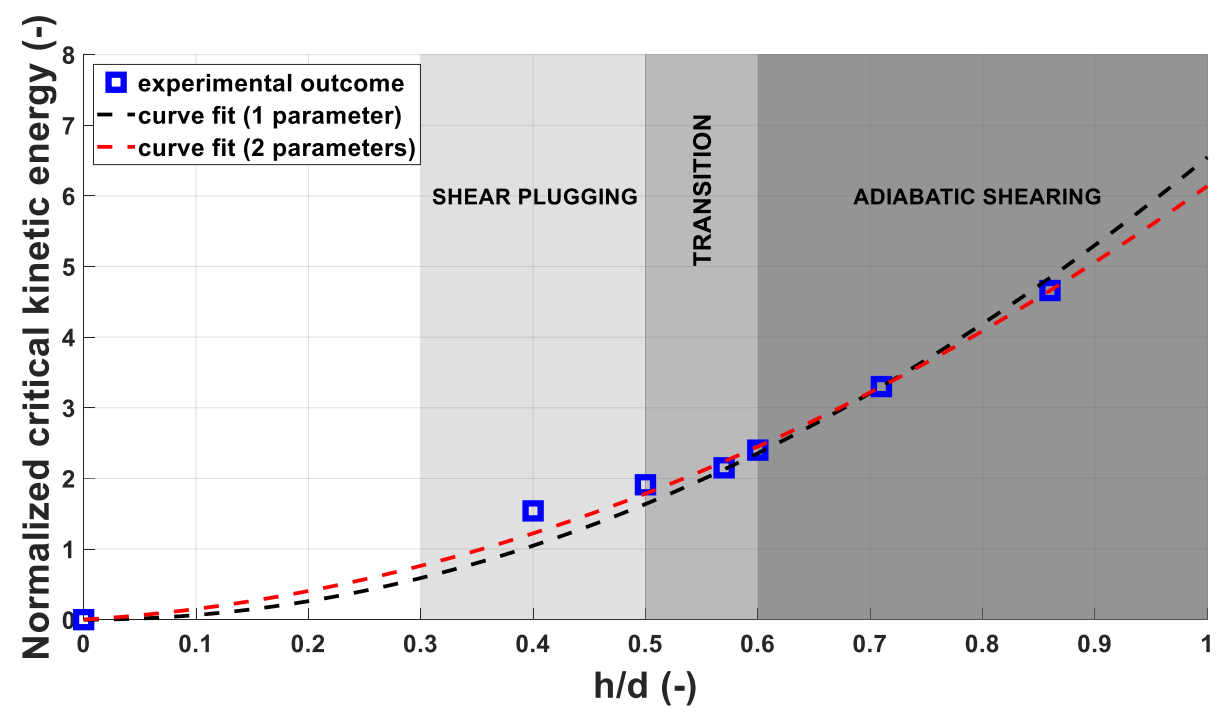

Figure 15. $\widetilde{E}_{\text {kin }}^{c r i t}$ over $h / d$ for every fragment-plate combination.

As reported by Equation (10), the value of $\widetilde{E}_{k i n}^{c r i t}$ is expressed by a two-term quadratic equation but, following the indications of Grady et al. [14], the linear term of the equation can be neglected and $\widetilde{E}_{k i n}^{c r i t}$ is then approximated by a one-term equation. The fitting parameters determined through a least square fit from the experimental data are listed in Table 6. It can be observed that, in the two-terms equation, the linear parameter $\varphi$ is one order of magnitude smaller than $\varepsilon$.

Table 6. Summary of parameters defined for the $\widetilde{E}_{\text {kin }}^{c r i t}$ equation.

\begin{tabular}{cccc}
\hline & $\varepsilon$ & $\varphi$ & $k$ \\
\hline Two-term eq. & 5.14 & 0.99 & 1.6 \\
One-term eq. & 6.55 & - & 2.1 \\
\hline
\end{tabular}


The estimated values of the multiplier $k$ are sensible. Preliminary Taylor impact tests have been performed and the results indicate the validity of the estimation. Furthermore, the estimations align significantly with the observations of Meyer et al. [17] and Stepanov [18] discussed in Section 2.3. Further details on the dynamic experimental and numerical characterization of MRE are described in a dedicated publication by the authors of this paper [22].

The graph in Figure 15 shows the two curves, respectively, in red and black. Both curves are accurate for values of $(h / d) \geq 0.57$, while a certain degree of discrepancy can be observed for lower ranges of $(h / d)$, as indicated by the graph. The red curve is still sufficiently accurate at the $h / d$ value of 0.5 , with an error of only $2 \%$, while the black curve shows an error in the order of $10 \%$ at the same abscissa. The inaccuracy becomes more significant at $h / d$ of 0.4 , reaching a value of $30 \%$ for the one-term form of the model.

Overall, the energy-based model is significantly reliable, giving accurate indications on the $\widetilde{E}_{k i n}^{c r i t}$. By neglecting the linear term of the model, the evaluations are still significantly accurate, indicating that the observations formulated by Grady et al. [14] can be applied to this case study.

It is worth noting that the energy-based model does not consider the physical aspects involved in the perforation process at the base of observations, as Børvik et al. [23] pointed out. In fact, Wen et al. [21] observed that the failure modes of plates impacted by blunt projectiles are dependent on the parameter $h / d$. In particular, in the area ranging from values of $h / d$ of 0.3 to 0.5 , the plates fail by simple shear plugging. As discussed in Section 3.2, minor dishing was observed in the area surrounding the craters in this zone. The deformation of the plate increases the energy dissipation and is reflected in the $\widetilde{E}_{k i n}^{c r i t}$ trend observed. The area going from values of $h / d \geq 0.6$, indicates the adiabatic shear plugging zone. Adiabatic Shear Bands (ASB) formation plays a crucial role in forming the plug, resulting in lower energies necessary for the perforation. The higher impact velocities necessary for perforation in this zone are responsible for the adiabatic shear plugging initiation [21]. The area ranging from $h / d$ of 0.5 to 0.6 , represents the transition zone. The subdivision just described represent a reference accepted by the scierntific community and perfectly alignes with the observations and conclusions of Børvik et al. [20,23] and Wen et al. [21]. However, a clear boundary between shear plugging, transition and adiabatic shearing cannot be defined, as the formation of ASB is an evolutionary process that starts from, approximately, $0.5 \mathrm{~h} / \mathrm{d}$ and is strongly affected by the variability of microstructural morphology that is intrinsic in every commercial product, as observed by $\mathrm{Xu}$ et al. [24], by Couque [25], Yiadom et al. [26] or Jo et al. [27].

Metallographic analyses were performed on sections of the perforated plates to validate the observations discussed in this chapter. Figure 16 shows the presence of ABS in a $3 \mathrm{~mm}$ plate impacted by a $5 \mathrm{~mm}$ MRE fragment at $1141 \mathrm{~m} / \mathrm{s}$. 


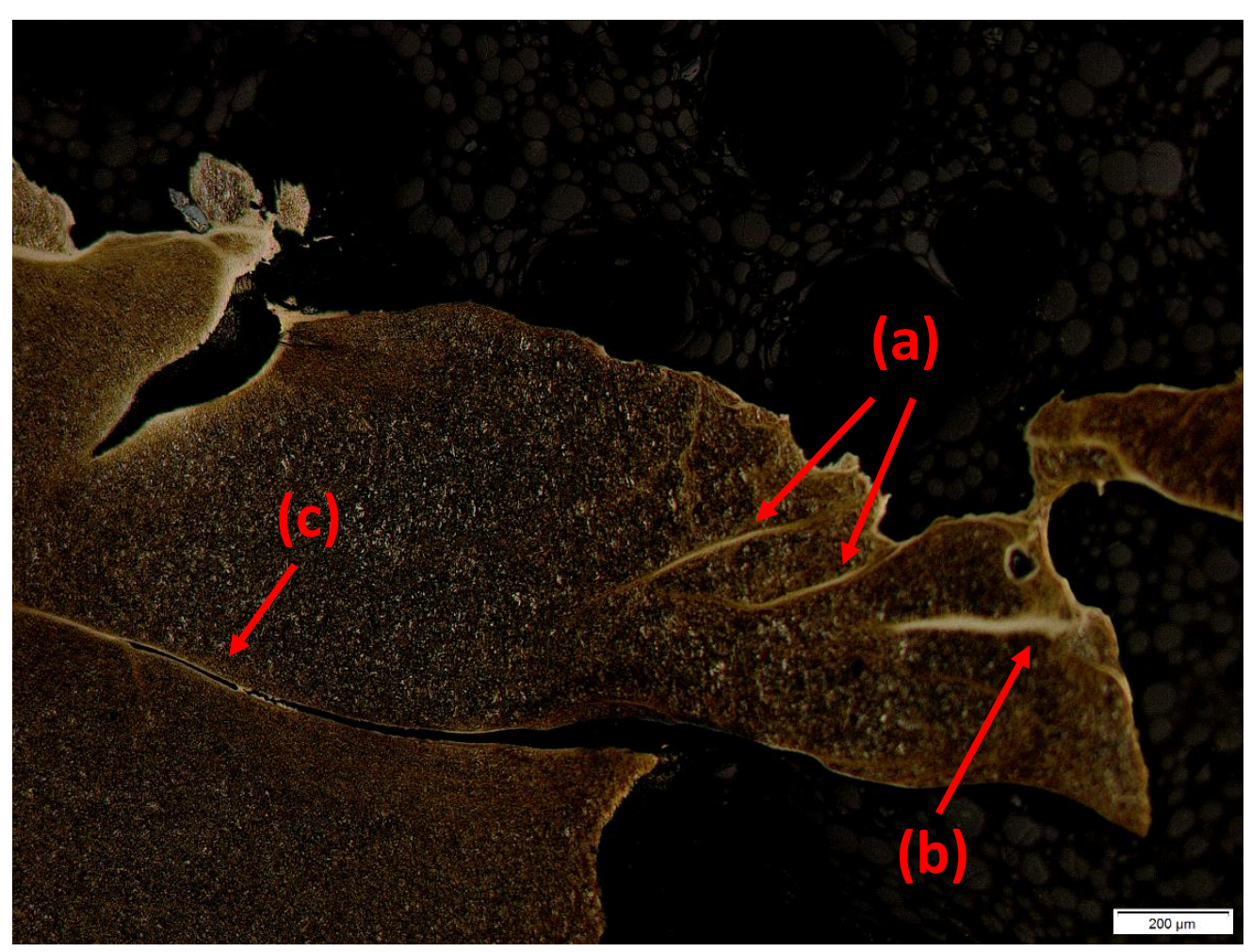

Figure 16. Metallographic analysis of plate impacted at $1141 \mathrm{~m} / \mathrm{s}$ with an $\mathrm{h} / \mathrm{d}=0.6$; (a) details of wide dASBs and gradual formation of tASB; (b) deformed shear bands (dASB), which are characteristic for early-stage deformations and shear; (c) narrow transformed shear band (tASB) created by further development of the dASB.

\section{Conclusions}

94 ballistic impact experiments were performed to collect relevant information on the behaviour of MRE fragments impacting armour steel plates with thicknesses ranging from $2 \mathrm{~mm}$ to $3 \mathrm{~mm}$. MRE samples are used as surrogate material of IRM, considering the affinity in terms of mechanical properties and macroscopic IIER effects. Quantitative parameters as $C I V, E_{K i n ~ c r i t}, \widetilde{E}_{\text {kin }}^{\text {crit }}$ and residual velocities were evaluated.

Prior to the set-up of the experiments, the influence of the pitch angle $(\alpha)$ on the impact outcomes was assessed. In particular, it was observed that for values of $\alpha$ up to $25^{\circ}$, the residual velocities measured were not affected significantly, as shown by the Recht-Ipson curves in Section 2.3.

The MRE fragments shattered upon impact, continuing the trajectory behind the perforated target plates. The comparison with inert steel fragments led to the conclusion that the failure mode influences the $C I V$ and $E_{K i n}$ crit quantification significantly, resulting in lower values of both CIV and $E_{\text {Kin crit }}$ for steel fragments. It was concluded that by increasing the thickness of the plates by $0.5 \mathrm{~mm}$, the kinetic energy loss increases by $10 \%$.

The failure mode observed in the plates is an indication of the energy necessary to perforate the plate. The interaction between the target plates and the MRE fragments at impact velocities greater than the $C I V$ resulted in shear plugging failure for all fragment/plate combinations. However, for lower values of $h / d$, simple shear plugging was preceded by minor dishing, while for the higher values of $h / d$ adiabatic shear plugging was observed, affecting the $C I V$ and $E_{\text {Kin }}$ crit.

Impact induced energy release was observed for all shots performed using MRE fragments. The IIER front spreads with velocities comparable with the residual velocities of the shattered fragment and, provided a stable flight, the ejected plugs.

The energy-based model developed is sufficiently accurate for the $\widetilde{E}_{\text {kin }}^{\text {crit }}$ evaluation for observed. The comparison between the two-terms form and the one-term form of the 
model indicates that the energy absorbed by the fragment for shattering is negligible, at least in first approximation, due to the brittle nature of MRE, confirming the assumptions formulated by Grady et al. [14].

Author Contributions: Conceptualisation, E.S.F., T.D.V.; methodology, E.S.F., M.S. and N.F.; validation, E.S.F., T.D.V.; formal analysis, E.S.F.; investigation, E.S.F. and N.F.; resources, M.S.; data curation, E.S.F. and N.F.; writing—original draft preparation, E.S.F.; writing—review and editing, E.S.F., M.S. and T.D.V.; visualisation, E.S.F.; supervision, T.D.V.; project administration, M.S.; All authors have read and agreed to the published version of the manuscript.

Funding: This research received no external funding.

Institutional Review Board Statement: Not applicable.

Informed Consent Statement: Not applicable.

Data Availability Statement: Data is contained within the article.

Conflicts of Interest: The authors declare no conflict of interest.

\section{References}

1. Aydelotte, B.B. Fragmentation and Reaction of Structural Energetic Materials. Ph.D. Thesis, Georgia Institute of Technology, Atlanta, GA, USA, 2013.

2. Aydelotte, B.; Braithwaite, C.; McNesby, K.; Benjamin, R.; Thadhani, N.; Williamson, D.M.; Trexler, M. A study of fragmentation in a Ni+Al structural energetic material. In AIP Conference Proceedings; American Institute of Physics: College Park, MD, USA, 2012; Volume 1426. [CrossRef]

3. Beason, M.T.; Gunduz, I.E.; Son, S.F. The role of fracture in the impact initiation of Ni-Al intermetallic composite reac-tives during dynamic loading. Acta Mater. 2017, 133, 247-257. [CrossRef]

4. Zhang, X.F.; Shi, A.S.; Qiao, L.; Zhang, L.; Guan, Z.W. Experimental study on impact-initiated characters of multifunc-tional energetic structural materials. J. Appl. Phys. 2013, 113, 083508. [CrossRef]

5. Lemaitre, J.; Desmorat, R. Engineering Damage Mechanics; Springer: Berlin/Heidelberg, Germany, 2005.

6. Waite, H.R.; Gortemoller, T.B. Study of the Terminal Effects of Pyrophoric Metal Fragments; Air Force Armament Lab.: Eglin, FL, USA, 1973.

7. Hillstrom, W.W. Impact Thresholds for the Initiation of Metal Sparking-Memorandum Report ARBRL-MR-02820; US ARMY Research and Development Command-Ballistic Research Laboratory: Aberdeen, MD, USA, 1978.

8. Cagle, C.; Hill, K.J.; Woodruff, C.; Pantoya, M.L.; Abraham, J.; Meakin, C. Target penetration and impact analysis of in-termetallic projectiles. Int. J. Impact Eng. 2020, 136, 103427. [CrossRef]

9. Zukas, J.A. High Velocity Impact Dynamics; Wiley: Hoboken, NJ, USA, 1990.

10. Rosenberg, Z.; Dekel, E. Terminal Ballistics; Springer: Berlin/Heidelberg, Germany, 2012.

11. Reinhardt, K.; Winkler, H. Cerium Mishmetal, Cerium Alloys, and Cerium Compounds. In Ullmann's Encyclopedia of Industrial Chemistry; Wiley: Hoboken, NJ, USA, 2012; Volume 8, pp. 41-56.

12. Recht, R.F.; Ipson, T.W. Ballistic Perforation Dynamics. J. Appl. Mech. 1963, 30, 384-390. [CrossRef]

13. Bratton, K.R.; Hill, K.J.; Woodruff, C.; Campbell, L.L.; Cagle, C.B.; Pantoya, M.L.; Magallanes, J.; Abraham, J.; Meakin, C. High Velocity Impact Testing of Intermetallic Projectiles. J. Dyn. Behav. Mater. 2020, 6, 236-245. [CrossRef]

14. Grady, D.E.; Winfree, N.A. Impact fragmentation of high-velocity compact projectiles on thin plates: A physical and statistical characterisation of fragment debris. Int. J. Impact Eng. 2001, 26, 249-262. [CrossRef]

15. Bethe, H.A. An Attempt at a Theory of Armor Penetration; Ordonance Laboratory Report (R492); Frankford Arsenal: Philadelphia, PA, USA, 1941.

16. Taylor, G.I. The formation and enlargement of a circular hole in a thin plastic plate. Quar. J. Mech. App. Math. 1948, 1, 103-124. [CrossRef]

17. Meyer, L.W.; Seifert, K.; Abdel-Malek, S. Behavior of Quenched and Tempered Steels under High Strain Rate Compression Loading. J. Phys. IV Colloq. 1997, 07, 571-576. [CrossRef]

18. Stepanov, G.V. Strength of Metals at High Strain Rates. Strength Mater. 2002, 34, 214-218. [CrossRef]

19. Aly, S.; Li, Q. Critical impact energy for the perforation of metallic plates. Nucl. Eng. Des. 2008, 238, 2521-2528. [CrossRef]

20. Børvik, T.; Leinum, J.R.; Solberg, J.K.; Hopperstad, O.S.; Langseth, M. Observationson shear plug formation in Weldox 460 E steel plates impacted by blunt-nosed projectiles. Int. J. Impact Eng. 2001, 25, 553-572. [CrossRef]

21. Wen, H.M.; Sun, W.H. Transition of Plugging Failure Modes for Ductile Metal Plates Under Impact by Flat-Nosed Projectiles\#. Mech. Based Des. Struct. Mach. 2010, 38, 86-104. [CrossRef]

22. Ferraro, E.S. Investigation on fragmentation of pyrophoric alloy samples during Taylor tests using SPH. Eur. Phys. J. Web Conf. 2021. accepted. 
23. Børvik, T.; Hopperstad, O.S.; Langseth, M.; Malo, K.A. Effect of target thickness in blunt projectile penetration of Weldox $460 \mathrm{E}$ steel plates. Int. J. Impact Eng. 2003, 28, 413-464. [CrossRef]

24. Xu, Y.; Zhong, W.; Chen, Y.; Shen, L.; Liu, Q.; Bai, Y.; Meyers, M. Shear localization and recrystallization in dynamic deformation of 8090 Al-Li alloy. Mater. Sci. Eng. A 2001, 299, 287-295. [CrossRef]

25. Couque, H. Adiabatic Shear Bands in Penetrators and Targets. In Adiabatic Shear Localization; Elsevier: Amsterdam, The Netherlands, 2012; pp. 247-266. [CrossRef]

26. Yiadom, S.B.; Khan, A.K.; Bassim, N. Effect of microstructure on the nucleation and initiation of adiabatic shear bands (ABSs) during impact. Mater. Sci. Eng. A 2014, 615, 373-394. [CrossRef]

27. Jo, M.C.; Kim, S.; Kim, D.W.; Park, H.K.; Hong, S.S.; Kim, H.K.; Kim, H.S.; Sohn, S.S.; Lee, S. Understanding of adiabatic shear band evolution during high-strain-rate deformation in high-strength armor steel. J. Alloys Compd. 2020, 845, 155540. [CrossRef] 